\title{
Bistable Nonlinear Energy Sink Using Magnets and Linear Springs: Application to Structural Seismic Control
}

\author{
Y. Y. Chen $\mathbb{D}^{1,{ }^{1,2}}$ W. Zhao $\left(\mathbb{D},{ }^{3}\right.$ C. Y. Shen $\mathbb{D}^{1,},{ }^{1,2}$ and Z. C. Qian ${ }^{1,2}$ \\ ${ }^{1}$ MOE Key Laboratory of Earthquake Resistance, Earthquake Mitigation and Structural Safety, \\ Earthquake Engineering Research \& Test Center, Guangzhou University, Guangzhou 510405, China \\ ${ }^{2}$ Guangdong Provincial Key Laboratory of Earthquake Engineering and Applied Technology, Guangzhou University, \\ Guangzhou 510405, China \\ ${ }^{3}$ MOE Key Laboratory of Disaster Forecast and Control in Engineering, School of Mechanics and Construction Engineering, \\ Jinan University, Guangzhou 510632, China
}

Correspondence should be addressed to Y. Y. Chen; yychen@gzhu.edu.cn

Received 18 March 2021; Accepted 29 July 2021; Published 11 August 2021

Academic Editor: Jiaxi Zhou

Copyright $\odot 2021$ Y. Y. Chen et al. This is an open access article distributed under the Creative Commons Attribution License, which permits unrestricted use, distribution, and reproduction in any medium, provided the original work is properly cited.

Nonlinear energy sink (NES) has proven to be very effective in reducing the vibration response of structures. In this paper, a magnetic bistable nonlinear energy sink (BNES) that composed of a guided moving mass attached with linear springs and permanent magnets is proposed. To assess the seismic control performance of the proposed BNES, a shear frame model equipped with the proposed BNES is compared with the same shear frame model equipped with an optimized cubic NES and with a linear tuned mass damper (TMD) system. The results show that, in the idealized situation, where the mass and stiffness is clearly defined (no uncertainty), the BNES can achieve similar performance as a thoroughly in-tuned TMD system. Moreover, in the detuned condition, due to broadband high internal resonance capability, the proposed BNES can outperform the linear TMD and the cubic NES. The study demonstrates that the proposed BNES can be used as an efficient passive vibration absorber for structural seismic control.

\section{Introduction}

Passive tuned mass dampers (TMDs) are efficient and lowcost devices to reduce the vibration response of structures. However, a traditional TMD system with linear stiffness is only effective within a narrow frequency range. With many practical conditions, such as structural uncertainties, material nonlinearity, and soil-structure interaction, it is very difficult to perfectly tune the TMD for a real practical application with uncertainties. More importantly, when the structure is experiencing severe earthquake shaking, high stiffness degradation can rapidly lead to undesirable detuning of the TMD system.

To improve the performance of the passive TMD, a nonlinear energy sink (NES) [1] has been developed. An NES is usually designed as a mass-spring-damper system attached to a primary structure, coupled with strongly nonlinear stiffness. Under dynamical response, the targeted energy transfers (energy pumping) from the primary structure to the designed NES can be triggered in wider frequency domains, enabling energy absorbing and dissipating in the NES device. Over the past twenty years, many types of NES have been developed. In general, an NES can be classified as follows: (1) NES with smooth stiffness [2-11], (2) NES with vibro-impact [12-16], and (3) other NES such as the NES with nonsmooth Saint-Venant terms $[17,18]$. The NES with smooth stiffness is the most studied NES. For example, the cubic NES [2-7] uses linear springs with nonlinear geometry to create the nonlinearity needed to cause the structural internal resonances under a wide frequency range. The track NES [8-10] utilizes a moving mass on a shapeable track to cause resonances of the building under seismic loads. The large-scale shake table experiment [19] shows the vibro-impact NES is totally more efficient 
than the traditional NES with smooth stiffness. Similar analysis [20] shows the performance of the track NES can be improved with additional impact mechanism. Even though a vibro-impact NES can improve the structure deformation, it creates high acceleration shocks at instance of impacts.

To overcome the aforementioned drawbacks of the NES with smooth stiffness, the bistable NES (BNES) [21-25], which can lead to higher efficient energy absorption, is proposed. The BNES can be configured by a movable mass linked with transverse springs that are compressed at their aligned position [21]. The BNES stiffness can thus be simulated approximately including negative linear and nonlinear stiffness components. Figure 1(a) shows the concept of a BNES device. In real application of BNES, due the compression force in the springs, they are prone to buckling, as shown in Figure 1(b)-1(d), which can lead to failure of BNES.

In this paper, a magnetic BNES device, utilizing magnets and linear springs, is proposed. The proposed configuration utilizes the bistable mechanism of BNES but avoids the bending buckling mechanism of the transverse springs. To properly model the dynamic behavior of the proposed BNES, a new BNES constitutive model is presented in this paper. In addition, the seismic behavior of the proposed BNES on a shear building is investigated. The performance of the BNES on a shear building is compared with the cubic NES and the TMD. The result shows the present BNES is generally superior to the cubic NES and the TMD in both the ideally tuned and the detuned conditions.

\section{Mechanism of the Present BNES}

Figure 2 shows the illustration of the proposed BNES. The proposed BNES uses two pairs of permanent magnets to replace the transverse springs in the traditional BNES (Figure 1), which will eliminate the buckling problem of the BNES device. A guided sliding mass block, two steel coil springs, and two pairs of permanent magnets are adopted to compose the proposed BNES device. The mass block is fixed on a pair of tube sliders, which are sleeved at a pair of parallel tubes grounded on primary structure, by means of linear roller guide bearings. The sliding friction on the tube can provide reasonable damping for the proposed BNES. Fixed coil springs are adopted as the linear spring to link the BNES mass and the pedestals grounded on the primary structure, providing the positive stiffness needed for the BNES. Obviously, the springs are much easier to be designed than transverse hinged springs, as they are linked with fixed connections and deform in the identical direction the NES mass moves. In the present design, all the magnets are considered in the same cuboid size. For each pair of the magnets, one is attached to a side of the mass block, while the other one is attached to a fixed pedestal grounded on primary structure. Thus, due to balance of the reaction force of the springs and the magnetic repulsions, the bistable restoration of the moving BNES mass can be generated.

Figure 3 shows the conceptual diagram and notation used to define the BNES device. Here, $u$ denotes the displacement drift of the BNES mass in the $x$-direction. It can be seen that each pair of magnets are paralleled and magnetized at opposite direction, so that their repulsive action can generate the instable static equilibrium $(u=0)$ as the BNES mass moves. It is obvious that the distance $(L)$ between the geometric centers of the cuboid magnets is critical to the repulsive force between them. To ensure the proposed NES has a positive linear stiffness $(k)$, linear springs are added to the NES mass to provide the positive linear stiffness (k). Consequently, two stable equilibriums $\left(u= \pm u_{c}\right)$ can be configured at both sides of the instable equilibrium, as shown in the constitutive curve in Figure 3. Thus, a negative stiffness interval of the restoration can be generated in the neighborhood range of $u=0$.

To establish the constitutive model of the BNES, the magnetic charge model [26] between two magnets is firstly considered. The magnetic polarizations are supposed to be rigid and uniform in each magnet, by which the analytical expression of the magnetic force can be established. To introduce the magnetic charge model, Figure 4 demonstrates a pair of magnets in the local Cartesian coordinate system $o$ $\alpha-\beta-\gamma$ for which the origin is set at the geometric center of the first magnet and the axes are parallel to the edges of the cuboid magnets. Defining the location variables of geometric center of the second magnet at $(\alpha, \beta, \gamma)$, the repulsive force $\mathbf{F}$ between the two magnets can be expressed by a three-dimensional vector, i.e.,

$$
F(\alpha, \beta, \gamma)=\frac{J \cdot J^{\prime}}{4 \pi \mu_{0}} \sum_{i=0}^{1} \sum_{j=0}^{1} \sum_{k=0}^{1} \sum_{l=0}^{1} \sum_{p=0}^{1} \sum_{q=0}^{1}(-1)^{i+j+k+l+p+q} \Phi\left(U_{i j}, V_{k l}, W_{p q}, r\right)
$$

where $\mathbf{J}$ and $\mathbf{J}^{\prime}$ denote the polarization vectors of the two magnets, respectively. $\mu_{0}$ denotes the vacuum permeability factor, which equals $4 \pi \times 10^{-7} \mathrm{H} / \mathrm{m}$. Each orthogonal component of the vector $\Phi$ in the coordinate system is as below: 


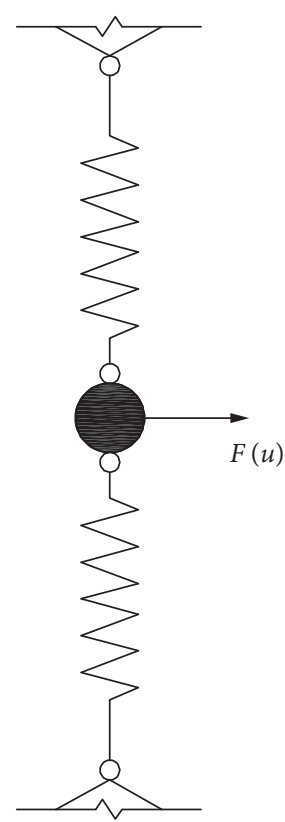

(a)

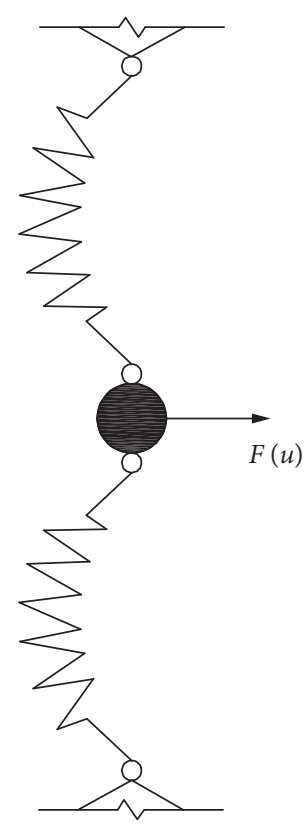

(b)

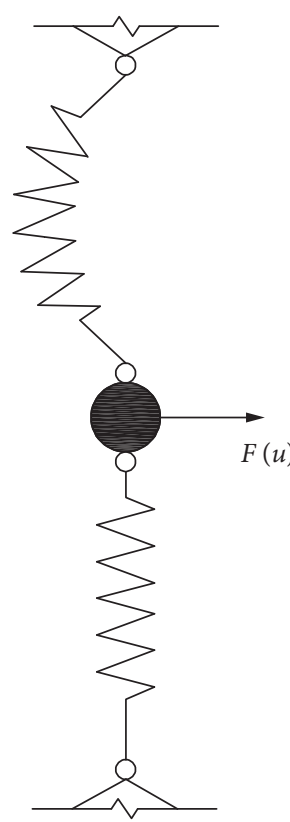

(c)

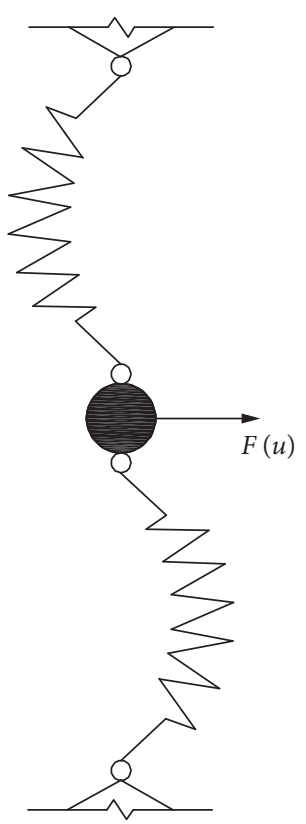

(d)

FIgURE 1: Configuration of (a) BNES using transverse springs and (b-d) its typical buckling forms.

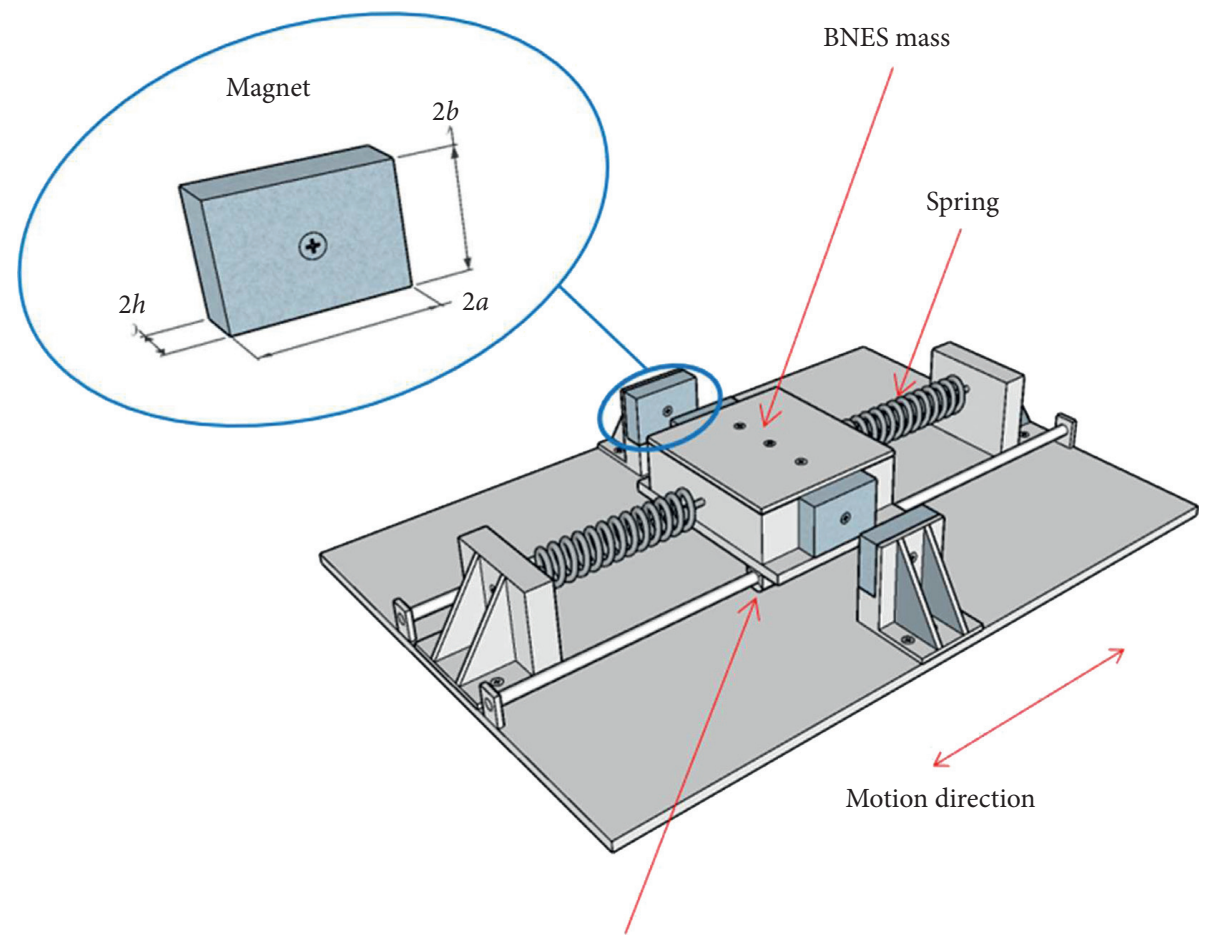

Linear roller guide bearings

FIGURE 2: Illustration of the proposed BNES device. 


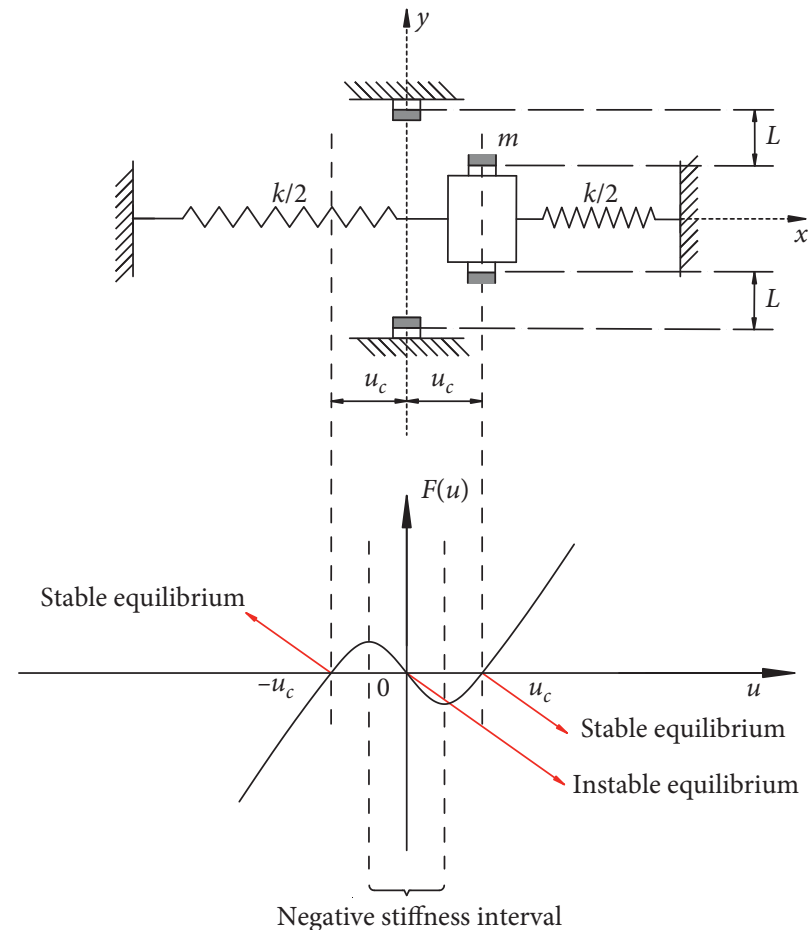

FIgURE 3: Schematic plane view and the restoring force curve of the BNES.

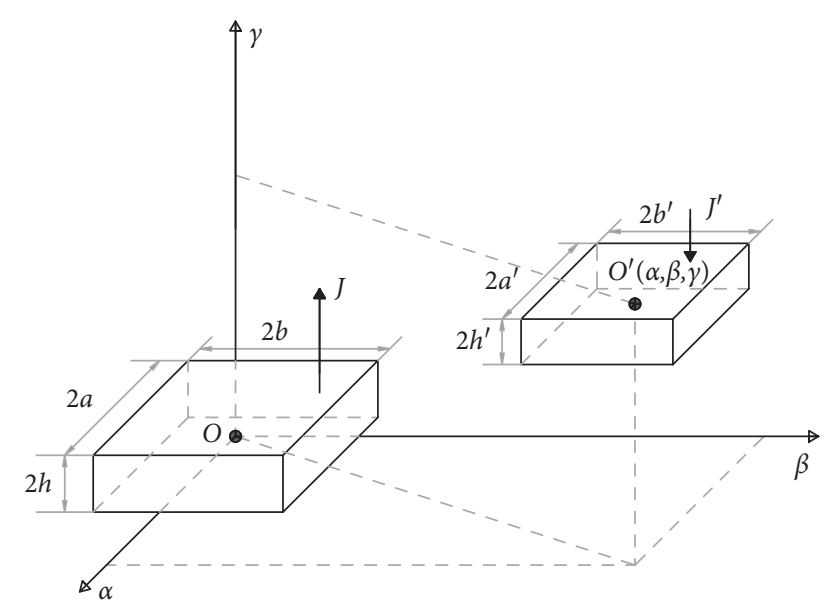

FIgUre 4: Two magnets in the local Cartesian coordinate system.

$$
\begin{aligned}
\Phi_{\alpha}(U, V, W, r)= & \frac{\left(V^{2}-W^{2}\right)}{2} \ln (r-U)+U V \ln (r-V) \\
& +V W \arctan \left(\frac{U V}{r W}\right)+\frac{r}{2} U,
\end{aligned}
$$

$$
\begin{aligned}
\Phi_{\beta}(U, V, W, r)= & \frac{\left(U^{2}-W^{2}\right)}{2} \ln (r-V)+U V \ln (r-U) \\
& +U W \arctan \left(\frac{U V}{r W}\right)+\frac{r}{2} V,
\end{aligned}
$$

$$
\begin{aligned}
\Phi_{\gamma}(U, V, W, r)= & -U W \ln (r-U)-V W \ln (r-V) \\
& +U V \arctan \left(\frac{U V}{r W}\right)-r W,
\end{aligned}
$$

where

$$
\begin{gathered}
U_{i j}=\alpha+(-1)^{j} a-(-1)^{i} a_{0}, \\
V_{k l}=\beta+(-1)^{l} b-(-1)^{k} b_{0}, \\
W_{p q}=\gamma+(-1)^{q} h-(-1)^{p} h_{0}, \\
r=\sqrt{U_{i j}^{2}+V_{k l}^{2}+W_{p q}^{2}},
\end{gathered}
$$

where $\mathbf{J}$ and $\mathbf{J}^{\prime}$ denote the polarization vectors of the two magnets, respectively. The vacuum permeability factor is $\mu_{0}=4 \pi \times 10^{-7} \mathrm{H} / \mathrm{m}$, and the dimensions of the magnets are $2 a^{\prime} \times 2 b^{\prime} \times 2 h^{\prime}$ and $2 a \times 2 b \times 2 h$.

Referring to Figure 3, the restoring force acting on the present BNES mass at its guided motion direction can be expressed as the combination of the spring force and the magnetic force, which is expressed as

$$
F=k u+2 F_{\beta}(u, 0, H) \text {. }
$$

Obviously, the constitutive curve of $F$ changes as the positions and properties of the springs and the magnets vary. Here, since the magnetic force between two magnets sharply diminishes along with the distance between them increases, the magnetic forces between the two pairs of magnets are neglected. Such simplification is reasonable because the 
distance between the two pairs of magnets can be easily set sufficiently large.

To investigate the effectiveness of the present BNES, the device is considered to be attached to the roof of a typical shear frame model shown in Figure 5, for which the governing equations can be formulated as

$$
\begin{aligned}
m_{1} \ddot{x}_{1}+c_{1} \dot{x}_{1}+k_{1} x_{1}+c_{2}\left(\dot{x}_{1}-\dot{x}_{2}\right)+k_{2}\left(x_{1}-x_{2}\right) & =-m_{1} \ddot{x}_{g}, \\
m_{2} \ddot{x}_{2}+c_{2}\left(\dot{x}_{2}-\dot{x}_{1}\right)+k_{2}\left(x_{2}-x_{1}\right)+c_{3}\left(\dot{x}_{2}-\dot{x}_{3}\right)+k_{3}\left(x_{2}-x_{3}\right) & =-m_{2} \ddot{x}_{g}, \\
& \vdots \\
m_{i} \ddot{x}_{i}+c_{i}\left(\dot{x}_{i}-\dot{x}_{i-1}\right)+k_{i}\left(x_{i}-x_{i-1}\right)-c_{N} \dot{u}-F_{N} & =-m_{i} \ddot{x}_{g}, \\
m \ddot{u}+c \dot{u}+F & =-m\left(\ddot{x}_{g}+\ddot{x}_{i}\right),
\end{aligned}
$$

where $m_{i}, c_{i}, k_{i}$, and $x_{i}$ denote the lumped mass, the equivalent viscous coefficient of structural inherent damping, the story shear stiffness, and the displacement of the ith floor, respectively. $c$ denotes the viscous coefficient of the equivalent linear damper coupled to the BNES. $\ddot{x} g$ denotes the acceleration of ground motion, and $u$ denotes the relative displacement drift of the BNES mass with respect to the roof of the primary structure. In the figure, $F^{\prime}$ means $\mathrm{d} F / \mathrm{d} u$, which is the nonlinear stiffness of the BNES.

\section{Performance Optimization}

3.1. Performance Measure. In this study, the performance of the BNES is evaluated by the ratio of $E / E_{0}$, where $E$ and $E_{0}$ are the energy dissipated by the primary structure with and without using the BNES, respectively. Equation (11) shows the formula for the energy dissipated by the primary structure, where $\dot{x}_{0}=0$, and $\dot{x}_{i}-\dot{x}_{i-1}$ denotes the relative velocity response of $(i-1)$ th floor and the $i$ th floor. Also, $T_{\text {end }}$ is the end time of the vibration. Obviously, the lower value of $E / E_{0}$ results in a more efficient energy absorption by the proposed BNES.

$$
E=\sum_{i=1}^{N} c_{i} \int_{0}^{T_{\text {end }}}\left(\dot{x}_{i}(t)-\dot{x}_{i-1}(t)\right)^{2} \mathrm{~d} t
$$

In addition, the story drift ratios $\triangle_{\mathrm{rms}} / \triangle_{0, \mathrm{rms}}$ and $\triangle_{\max } /$ $\triangle_{0, \max }$ are also adopted to evaluate the control performance; where $\triangle_{\text {rms }}$ and $\triangle_{0 \text {,rms }}$ denote the enveloping values of the root mean square (RMS) of historical story drift response for all the stories, with and without control, respectively. $\triangle_{\max }$ and $\triangle_{0, \max }$ denote the enveloping values of peak story drift for all the stories, with and without control, respectively. Lower values of these ratios correspond to more efficient story drift control by the proposed BNES.

Therefore, we define the minimization objective index as the summation of weighted ratios of the performance measures shown above. Equation (12) shows the index to be optimized.

$$
I=\eta_{1} \frac{E}{E_{0}}+\eta_{2} \frac{\Delta_{\mathrm{rms}}}{\Delta_{0, \mathrm{rms}}}+\eta_{3} \frac{\Delta_{\max }}{\Delta_{0, \max }},
$$

where $\eta_{1}, \eta_{2}$, and $\eta_{3}$ are the normalized weighting factor. In the following study, $\eta_{1}, \eta_{2}$, and $\eta_{3}$ are chosen as 1 , where all the terms carried the same weight.

3.2. Optimization Procedure. A one-story shear frame model (SDOF primary structure, Figure 6(a)) and a two-story shear frame model (TDOF primary structure, Figure 6(b)) are adopted for the case studies to assess the performance of the BNES control system. Table 1 lists the properties of the shear frames. The BNES device is considered to be installed on top of the frame.

The NdFeB permanent magnet of grade N44 (an alloy of neodymium, iron, and boron formed as the Nd2Fe14B tetragonal crystalline solid) is considered for the BNES device because of its high magnetic polarization intensity in compact dimensions. Here, $J=-J^{\prime}=1.34$ Tesla. As the dimensions of the magnets significantly affect the magnetic force, they are considered optimized parameters. The dimension variables of each magnet are identical and are illustrated in the enlarged local image in Figure 2. They include the side lengths $(2 a, 2 b)$ of the cross sections of the magnet, and the thickness $(2 h)$ paralleled to its magnetized direction. Furthermore, the position distances $(L)$ of the magnets, the stiffness coefficient $(k)$ of the linear spring, and the viscous coefficient $(c)$ of the coupled damping are also considered to be optimized. Therefore, as listed in Table 2, totally 6 optimization parameters for the BNES device are identified. These parameters will determine the constitutive curve of the BNES and consequently affect the internal resonance behavior of the control system. Considering feasibility and installation space restriction according to the shear frame model, the searching ranges and numerical step sizes for the parameter optimization are listed in Table 2.

The previous studies [1-20] usually adopted initial impulsive ground motion to evaluate the efficiency of the NES systems. Such simplification avoids uncertainty of seismic wave selection and reasonably reduces the optimization calculation cost. Thus, in the present optimization, we also inputted a velocity as the initial vibration energy to the primary structure for the optimization parameter assessment. Considering the typical velocity response spectrum of seismic intensity and the scaled model response, the initial 


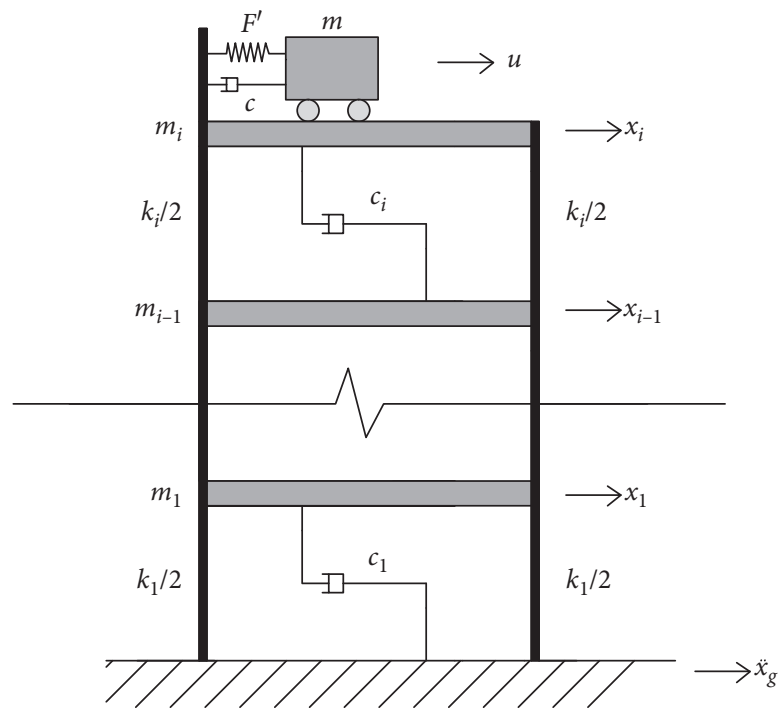

FIGURE 5: Conceptual layout of the primary structure attached with the BNES.

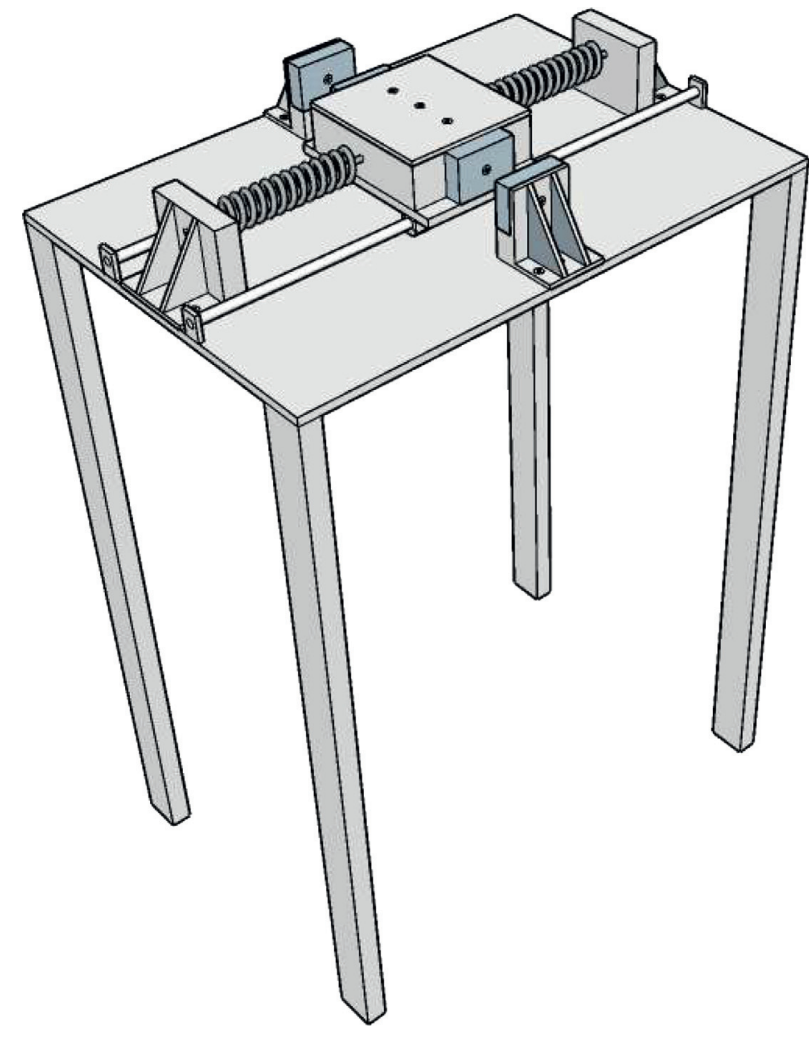

(a)

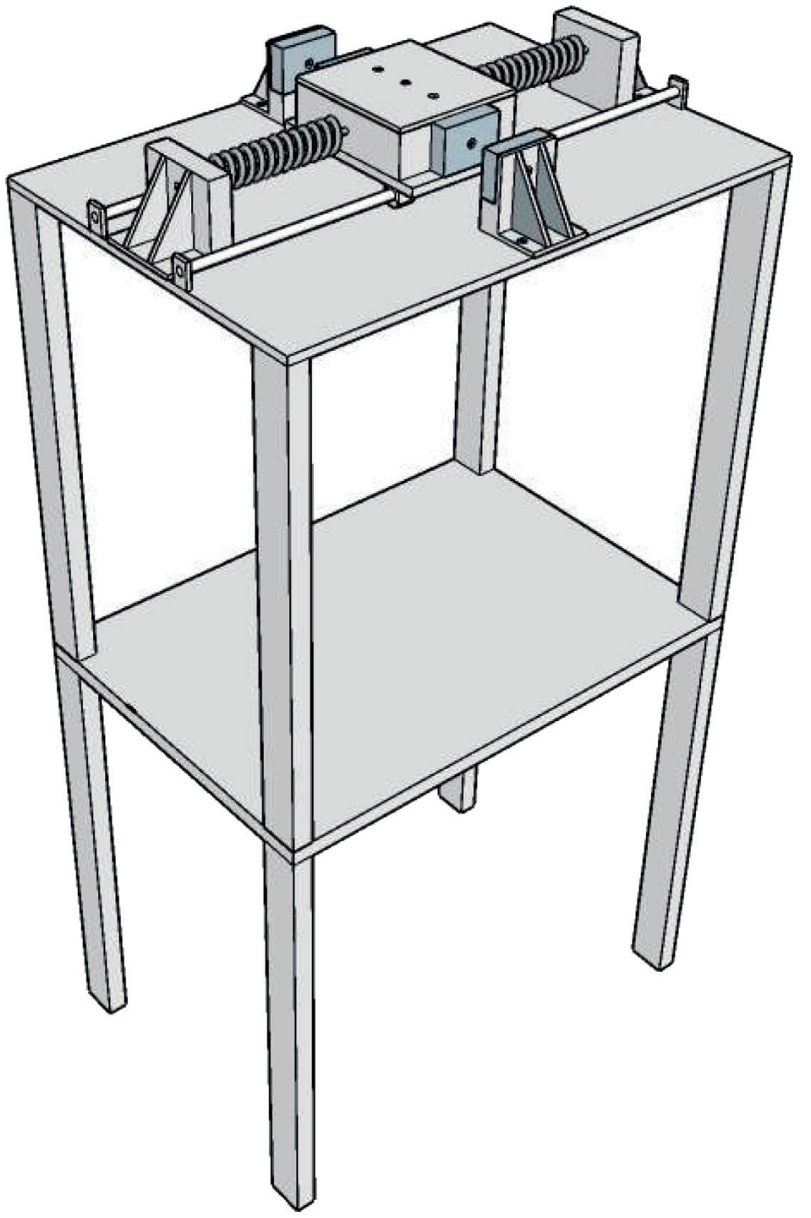

(b)

Figure 6: The shear frame models attached with the BNES device: (a) SDOF primary structure and (b) TDOF primary structure.

velocity value is given as $0.2 \mathrm{~m} / \mathrm{s}$. By the fourth-order Runge-Kutta numerical simulation for equation (10), exhausting trials are numerically conducted for every possible combination of the parameters in their searching ranges, to find out the best combination values of the parameters for the minimum $I$. As the numerical models we 
TABle 1: Properties of the primary structure.

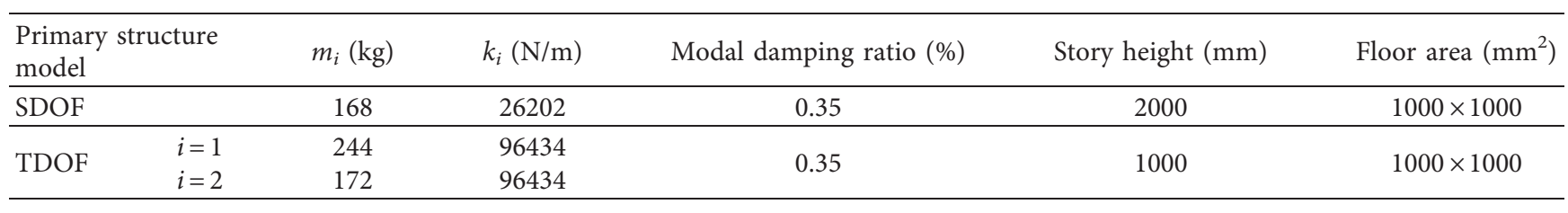

TABle 2: Optimization parameters of the control devices.

\begin{tabular}{|c|c|c|c|c|c|c|}
\hline \multirow{2}{*}{ Device type } & & \multirow{2}{*}{ Parameter } & \multirow{2}{*}{ Searching range } & \multirow{2}{*}{ Searching step size } & \multicolumn{2}{|c|}{ Optimal value } \\
\hline & & & & & For SDOF & For TDOF \\
\hline \multirow{6}{*}{ BNES } & & $2 a(\mathrm{~mm})$ & $10-200$ & \multirow{4}{*}{10} & 100 & 200 \\
\hline & & $2 b(\mathrm{~mm})$ & $10-200$ & & 70 & 80 \\
\hline & Magnet & $2 h(\mathrm{~mm})$ & $10-50$ & & 20 & 30 \\
\hline & & $L(\mathrm{~mm})$ & $0-300$ & & 90 & 80 \\
\hline & Spring & $k(\mathrm{~N} / \mathrm{mm})$ & $0-100$ & 0.002 & 0.951 & 3.439 \\
\hline & Damper & $c(\mathrm{~N} \cdot \mathrm{s} / \mathrm{m})$ & $0-100$ & 0.02 & 30.52 & 76.43 \\
\hline \multirow{3}{*}{\multicolumn{2}{|c|}{ Cubic NES }} & $k(\mathrm{~N} / \mathrm{mm})$ & $0-100$ & 0.002 & 6.794 & 33.800 \\
\hline & & $l(\mathrm{~mm})$ & $0-100$ & 10 & 80 & 90 \\
\hline & & $c(\mathrm{~N} \cdot \mathrm{s} / \mathrm{m})$ & $0-100$ & 0.02 & 21.54 & 97.50 \\
\hline \multirow{2}{*}{ TMD } & & $k(\mathrm{~N} / \mathrm{mm})$ & $0-100$ & 0.002 & 1.192 & 3.446 \\
\hline & & $c(\mathrm{~N} \cdot \mathrm{s} / \mathrm{m})$ & $0-100$ & 0.02 & 25.38 & 80.62 \\
\hline
\end{tabular}

used here are low-degree-of-freedom models, the exhausting calculation workload for the optimizations is still acceptable. For more complicated models such as many practical engineering structures, efficient optimization algorithms can be applied to determine the parameters of the present BNES.

For the following comparison study in Section 4, similar optimization procedures are also applied to optimize the typical cubic NES and the linear TMD systems (Figure 7), with their optimization parameters are listed in Table 2. Here, the auxiliary mass $(m)$ of all the control systems are identically chosen as $5 \%$ of the primary structure, so that the control performances of the TMD, the cubic NES, and the present BNES can be fairly compared, under the same primary structure and the same auxiliary mass level. Consequently, all the optimal values are derived and listed in the last two columns of Table 2 .

\section{Control Performance Study}

In this section, 28 ground motion records listed in Table 3 are used to assess the control performances of the optimized systems. As seismic excitations in the real environment are unpredictable and the stiffness of structures can degrade due to seismic damages, the comparison studies also focus on the performances of the system when the structural stiffnesses and the peak ground accelerations (PGA) change. Control performance of the optimized BNES is investigated and compared with those of the optimized cubic NES and TMD. Transient internal resonance behaviors are observed to interpret the essential working mechanism of the systems.

4.1. Performance of the One-Story Structure. The seismic responses of the SDOF primary structure with the optimized control systems are investigated in this section. For the ideal conditions, the RMSs of story drift history under the seismic excitations are summarized in Figure 8. It can be seen that, because of the resonance, the in-tuned linear TMD system generally possesses high efficiency in structural control, which verifies the viewpoint by Wierschem et al. [6]. On the other hand, high story drift suppression effect can also be observed in the results by the present BNES control. The reduction amplitudes by the in-tuned TMD control and by present BNES control are similar. This is not found in previous seismic control studies by NES with smooth stiffness. The cubic NES system shows much lower efficiency in the comparisons with the BNES. In some cases, the story drifts of the primary structure with the cubic NES even exceeds 2 times of those by TMD or BNES systems, indicating that the cubic NES is less effective. The presented BNES can significantly improve the seismic control effect of the NES system with smooth stiffness. Figure 9 demonstrates the story drift histories of the primary SDOF under the typical seismic wave excitations. From the figure, it can be seen that the seismic response control by the TMD or by the BNES is obviously more preferable compared with cubic NES. In total, the BNES performs equally as the TMD performs in the perfect in-tuned conditions.

To assess the robustness behavior, Figure 10 presents the RMSs of story drift responses with the stiffness of the primary structure lost in 50\%. Compared to Figure 8, the BNES systems can keep the performance, while the detuned TMD and the cubic NES give unsatisfactory performance. These results verified the high sensitiveness in the tuning condition of the traditional linear TMD system. Figure 11 demonstrates the story drift histories of the SDOF primary structure with $50 \%$ stiffness loss under severe seismic waves. The comparison of Figures 9 and 11 indicates that, as the 


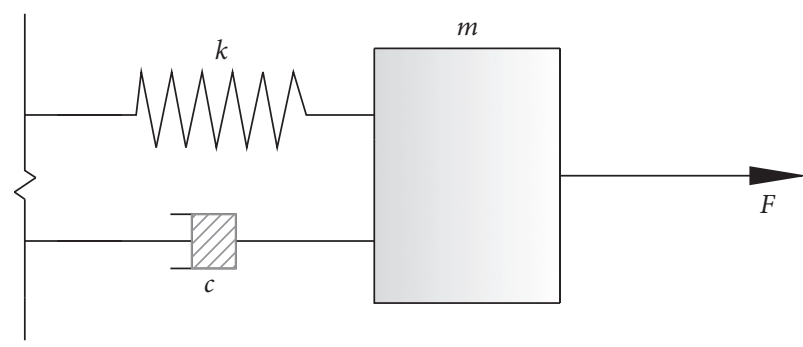

(a)

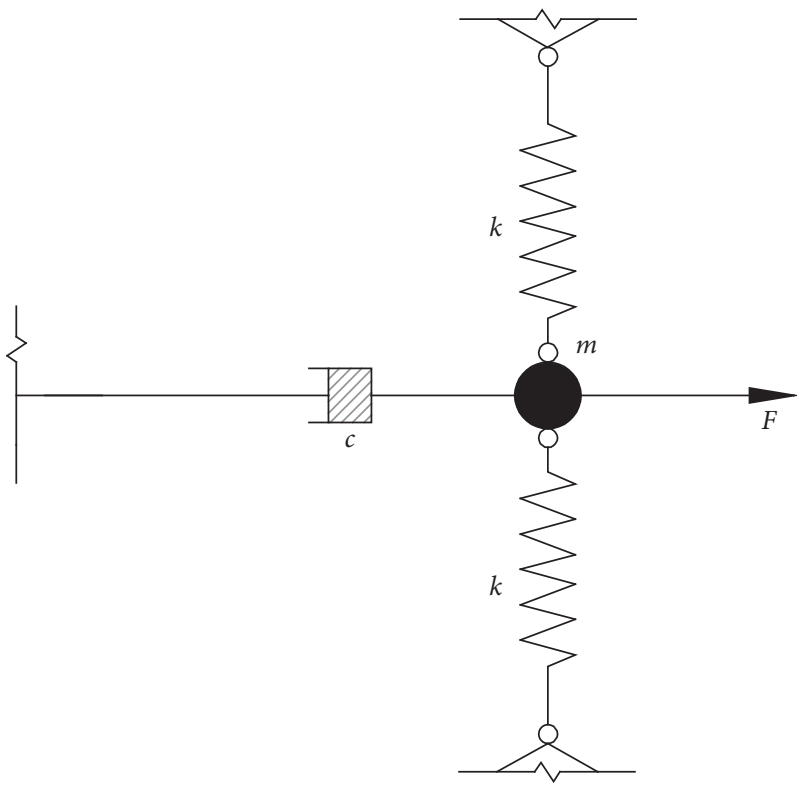

(b)

Figure 7: Conceptual layout of the (a) TMD and (b) cubic NES

TABLE 3: Input seismic records for performance assessment.

\begin{tabular}{|c|c|c|c|c|}
\hline No. & Earthquake & Station & Predominant frequency $(\mathrm{Hz})$ & PGA (g) \\
\hline 1 & \multirow{4}{*}{ San Fernando, 1971, USA } & \multirow{4}{*}{ Lake Hughes \#1 } & \multirow{4}{*}{1.50} & 0.1 \\
\hline 2 & & & & 0.2 \\
\hline 3 & & & & 0.3 \\
\hline 4 & & & & 0.4 \\
\hline 5 & \multirow{4}{*}{ Imperial Valley, 1979, USA } & \multirow{4}{*}{ Cerro Prieto } & \multirow{4}{*}{1.62} & 0.1 \\
\hline 6 & & & & 0.2 \\
\hline 7 & & & & 0.3 \\
\hline 8 & & & & 0.4 \\
\hline 9 & \multirow{4}{*}{ Whittier Narrows, 1987, USA } & \multirow{4}{*}{ Carson-Water St } & \multirow{4}{*}{1.29} & 0.1 \\
\hline 10 & & & & 0.2 \\
\hline 11 & & & & 0.3 \\
\hline 12 & & & & 0.4 \\
\hline 13 & \multirow{4}{*}{ Loma Prieta, 1989, USA } & \multirow{4}{*}{ Treasure Island } & \multirow{4}{*}{1.56} & 0.1 \\
\hline 14 & & & & 0.2 \\
\hline 15 & & & & 0.3 \\
\hline 16 & & & & 0.4 \\
\hline 17 & \multirow{4}{*}{ Northridge, 1994, USA } & \multirow{4}{*}{ Hemet-Ryan Airfield } & \multirow{4}{*}{1.56} & 0.1 \\
\hline 18 & & & & 0.2 \\
\hline 19 & & & & 0.3 \\
\hline 20 & & & & 0.4 \\
\hline 21 & \multirow{4}{*}{ Kobe, 1995, Japan } & \multirow{4}{*}{ HIK } & \multirow{4}{*}{1.71} & 0.1 \\
\hline 22 & & & & 0.2 \\
\hline 23 & & & & 0.3 \\
\hline 24 & & & & 0.4 \\
\hline 25 & \multirow{4}{*}{ Chi-Chi, 1999, China } & \multirow{4}{*}{ CHY008 } & \multirow{4}{*}{0.38} & 0.1 \\
\hline 26 & & & & 0.2 \\
\hline 27 & & & & 0.3 \\
\hline 28 & & & & 0.4 \\
\hline
\end{tabular}

stiffness degrades, the present BNES system can still keep efficient response suppression for the primary structure in a certain level, but the TMD system and the cubic NES system obviously lose efficiency.
Figure 12 presents the response trends with respect to stiffness degradation and PGA variation. Figure 12(a)-12(c) indicates that, as the stiffness degrades from $100 \%$ to $50 \%$ of the designed value, the BNES totally keeps the strongest 


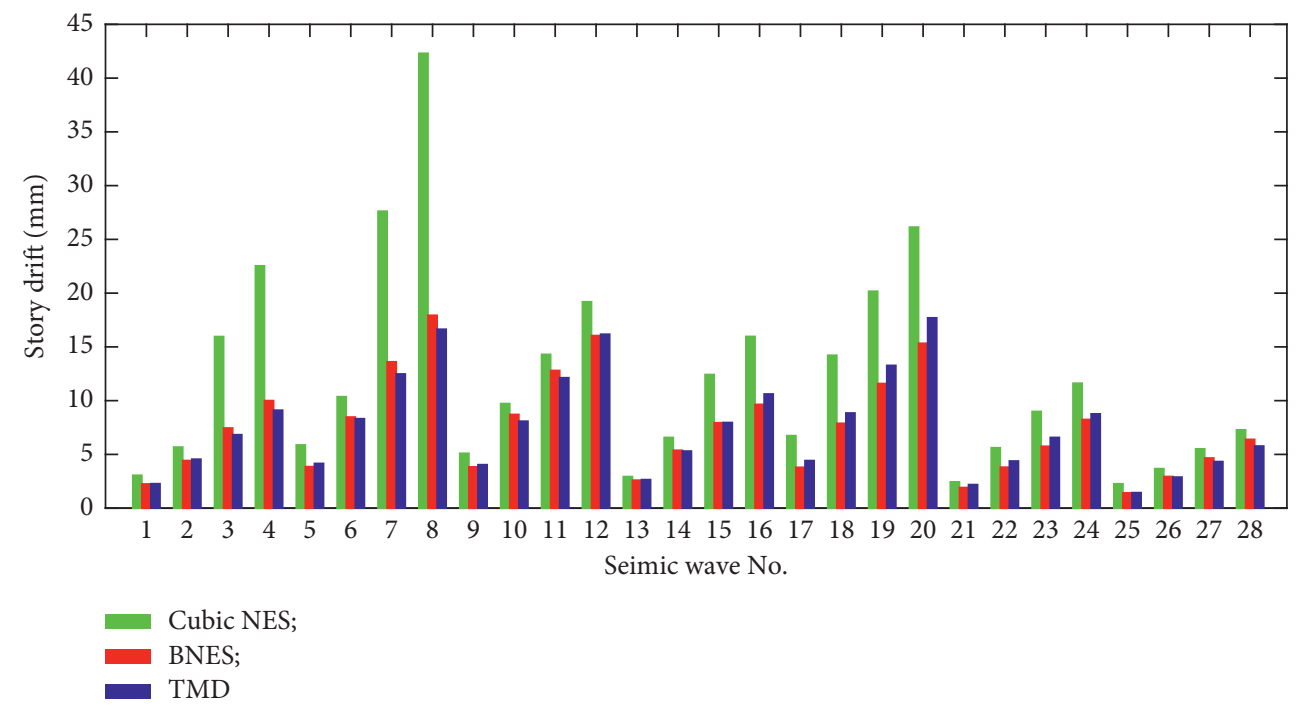

FIGURE 8: RMSs of story drift of the SDOF primary structure under the ideal condition.

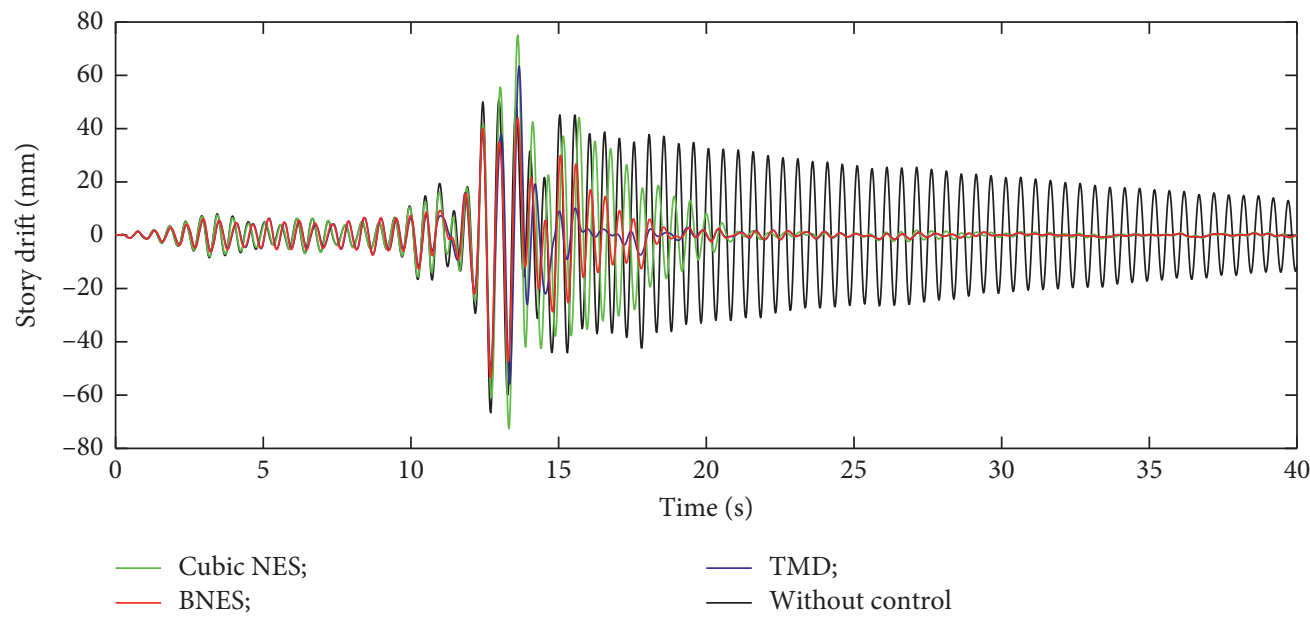

(a)

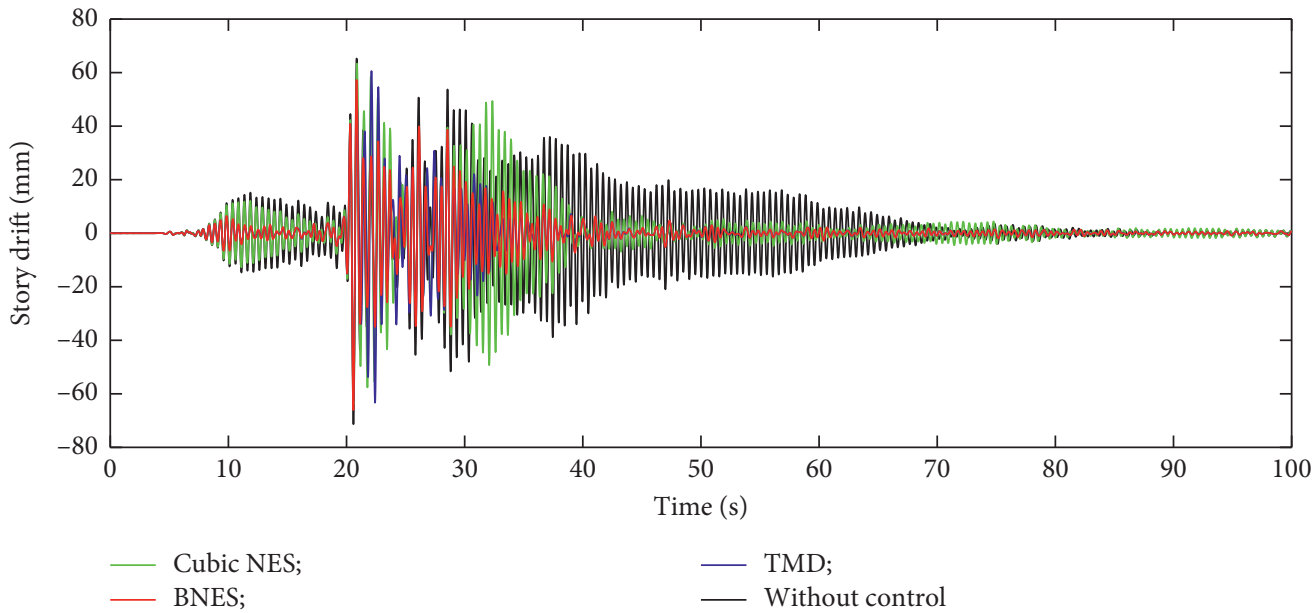

(b)

Figure 9: Continued. 


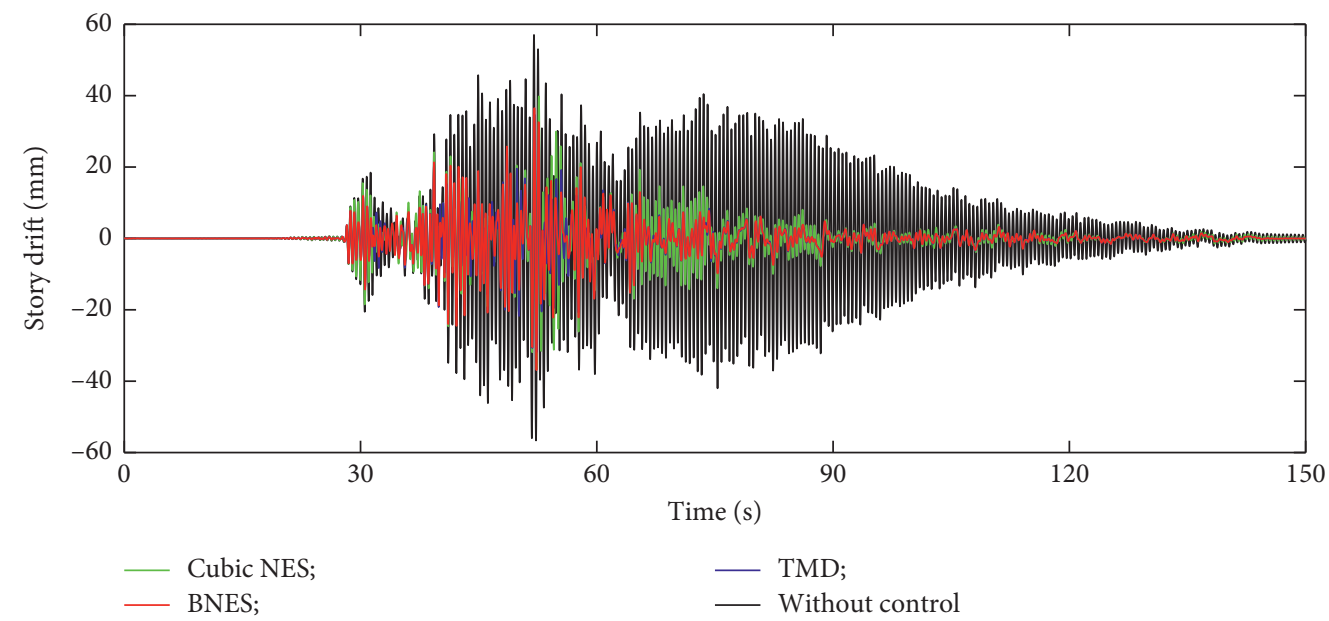

(c)

FIGURE 9: Story drift histories of the SDOF primary structure under the ideal condition: (a) Loma Prieta, 0.3 g; (b) Kobe, 0.3 g; (c) Chi-Chi, $0.3 \mathrm{~g}$.

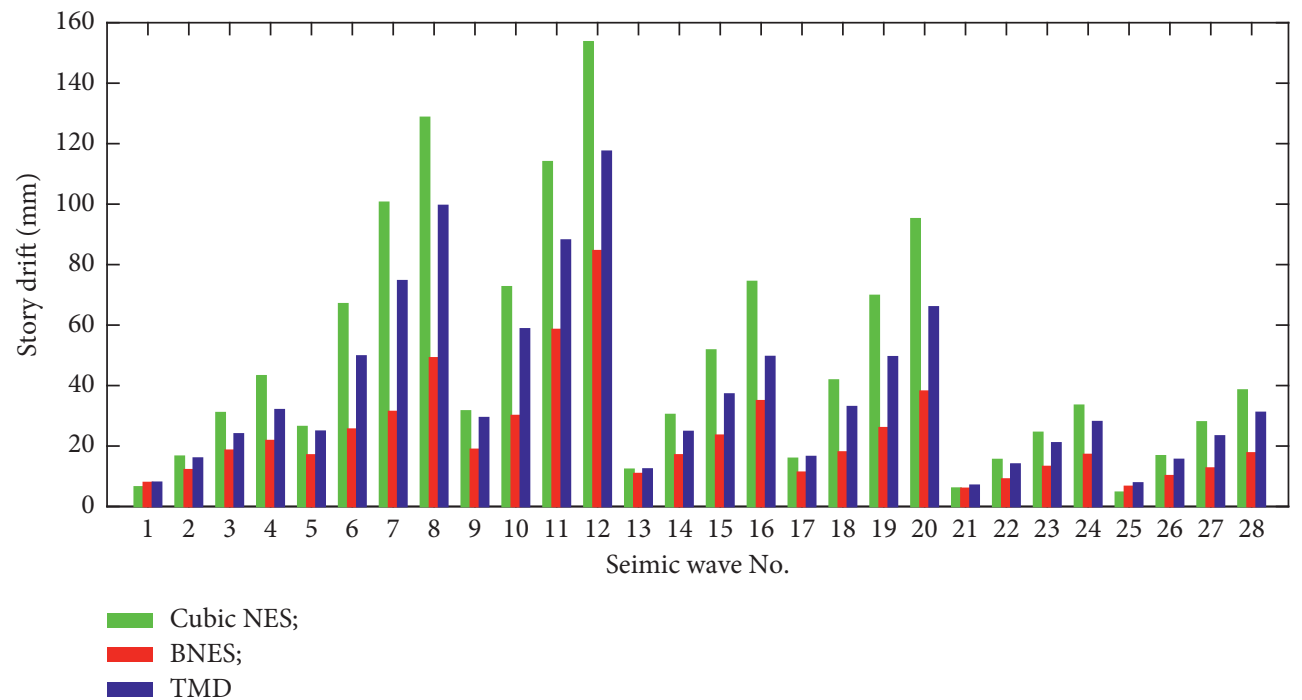

FIGURE 10: RMSs of story drift of the SDOF primary structure with $50 \%$ stiffness loss.

robustness to control energy response of the primary structure over the variation range. In particular, it can be observed in Figure 12(a)-12(c) that in some cases, the energy response under cubic NES control even exceeds that without control. Similar behaviors can also be observed in Figures 12(d)-12(f), which displays the robustness of the systems for story drift control. The figures totally underline that the BNES system is preferable especially for seismic control with stiffness degradation of the primary structure.

Figure 12(g)-12(i) investigates the robustness with respect to PGA variation, under in-tuned conditions. As the PGA value increases from 0 to $0.6 \mathrm{~g}$, the energy responses of the primary structure increase. As seen in the figure, the cubic NES is sensitively energy-dependent, while the TMD system maintains the energy response increasing at a lower level due to the ideal in-tuned condition. Particularly, from
Figure 12(g)-12(i), it can also be observed that, although the NES system is energy-dependent [1], considerable robustness improvement of NES with respect to PGA variation can be derived by using the present BNES system, as the energy response of the primary structure is reduced to a level similar to that with the TMD control.

To investigate the resonance evolution between the primary structure and the attached device, numerical wavelet transforms using the Morlet mother wavelet are conducted for the displacement response histories. Figure 13(a)-13(g) demonstrates the wavelet transforms spectrum of the systems under Loma Prieta wave excitation. The spectrums display the frequency distributions evaluated during the seismic excitation in gradient cloud graphs. From Figure 13(a) we can see that typical characteristics of a linear SDOF system without control can be verified, in which the 


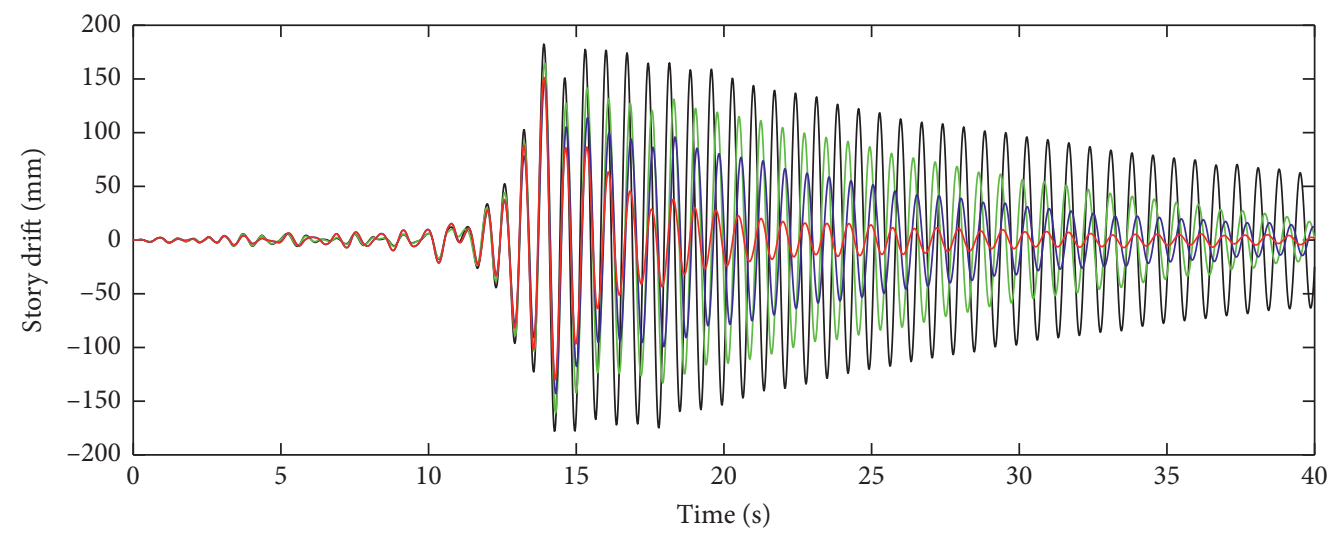

$\begin{array}{ll}\text { Cubic NES; } & \text { TMD; } \\ \text { BNES; } & - \text { Without control }\end{array}$

(a)

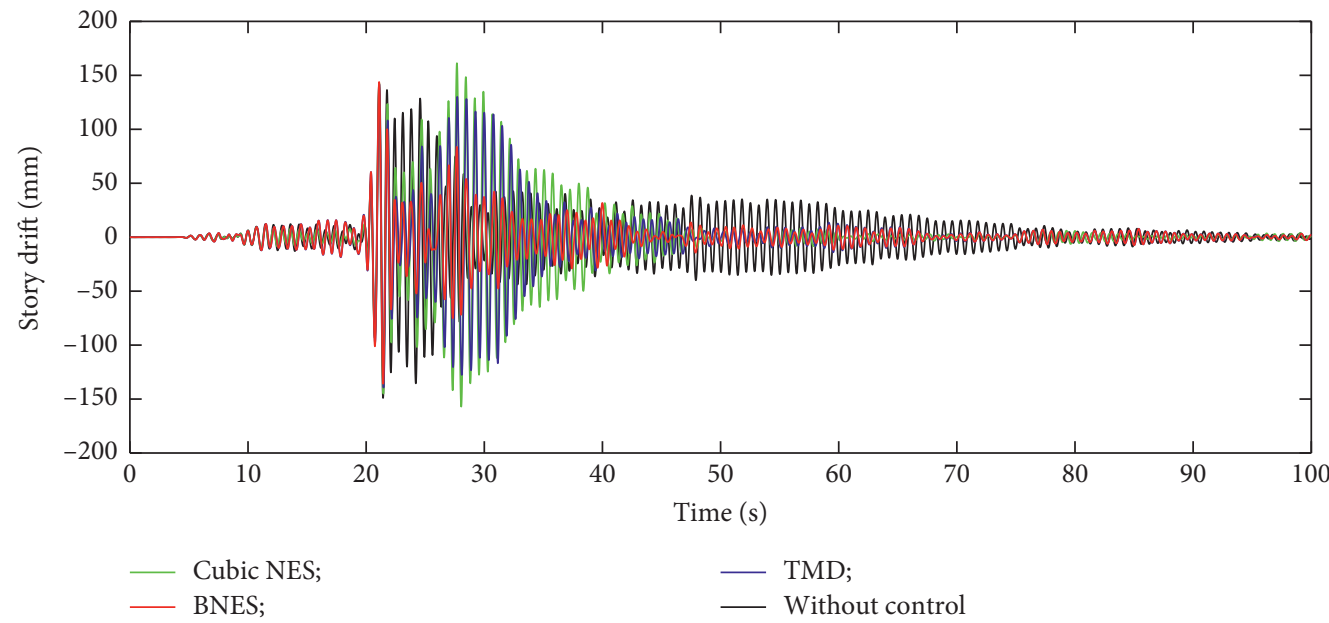

(b)

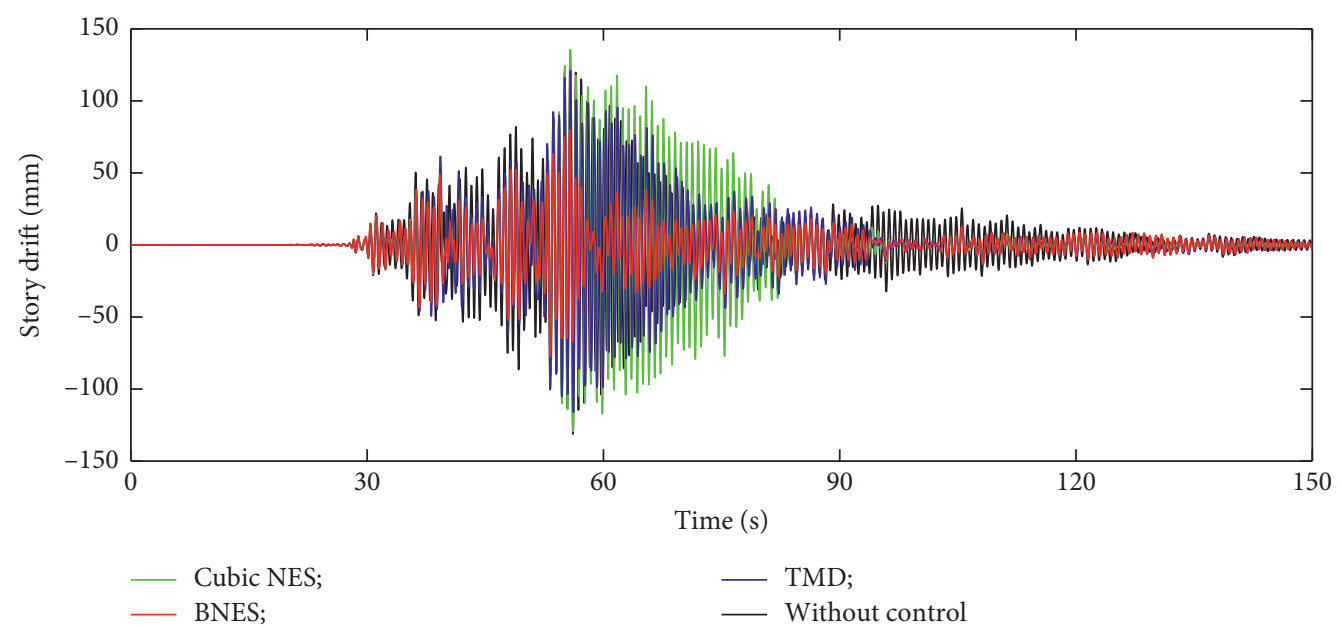

(c)

FIGURE 11: Story drift histories of the SDOF primary structure with 50\% stiffness loss: (a) Loma Prieta, 0.3 g; (b) Kobe, 0.3 g; (c) Chi-Chi, $0.3 \mathrm{~g}$.

dominant energy constantly response nearly at its natural frequency during the whole seismic response history. The well-known working mechanism of TMD, which tunes the vibration response nearly at the identical frequency, can be verified in Figure 13(b) and 13(c). Through the thorough tuning, a large amount of vibration energy is 


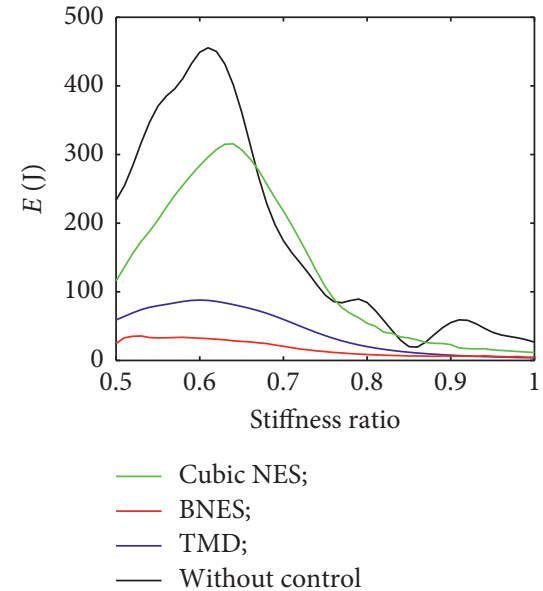

(a)

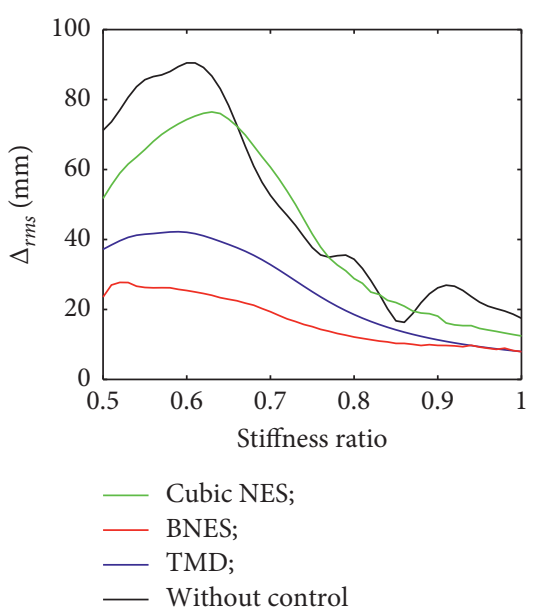

(d)

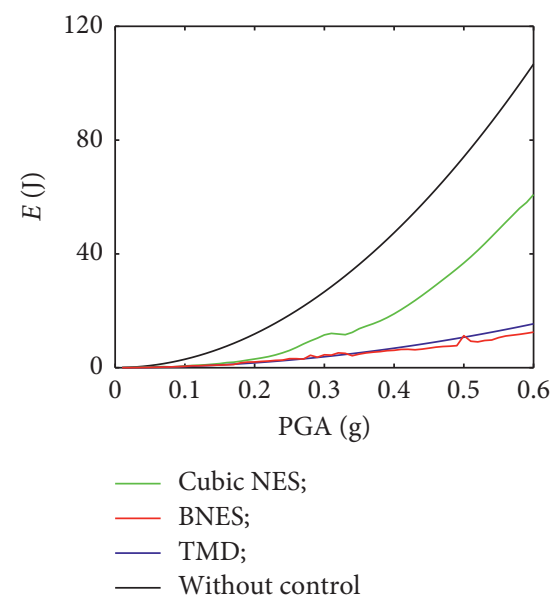

(g)

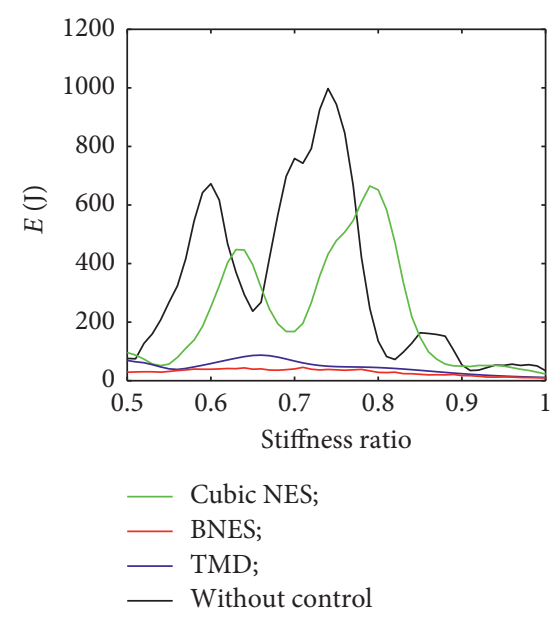

(b)

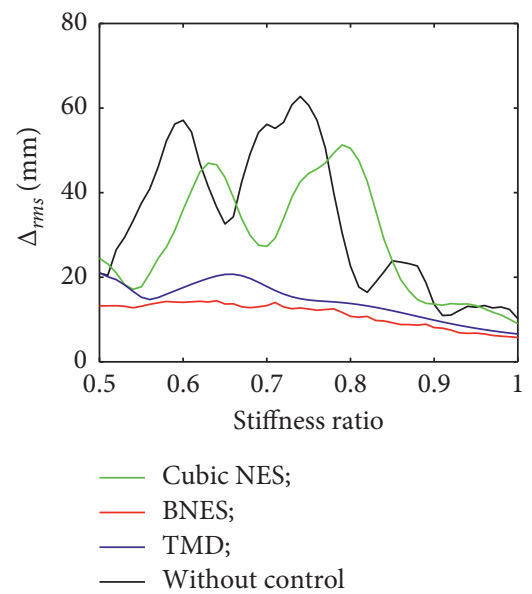

(e)

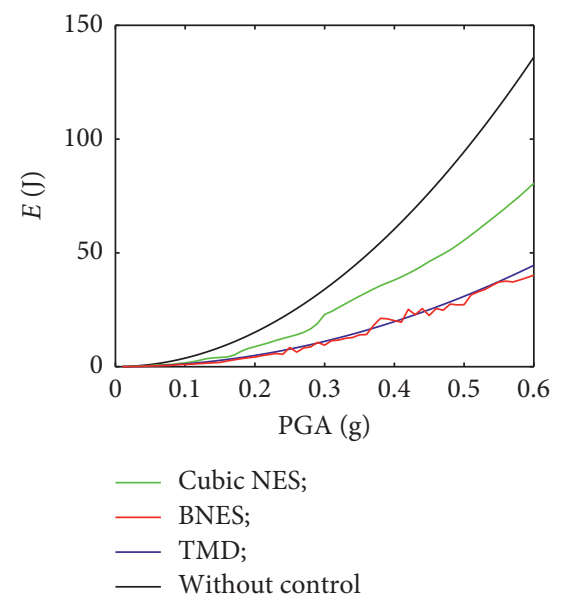

(h)

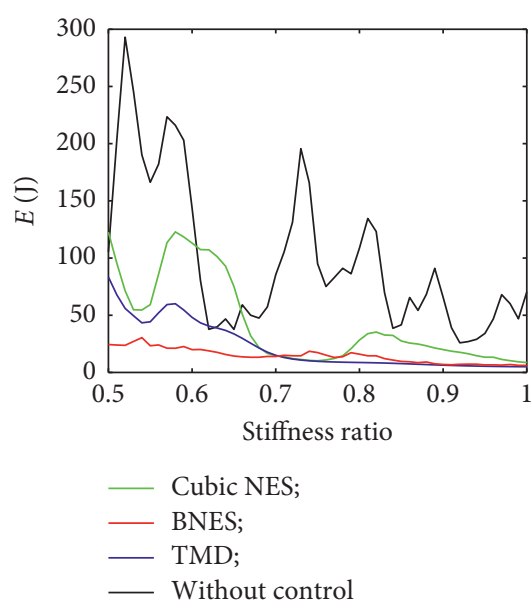

(c)

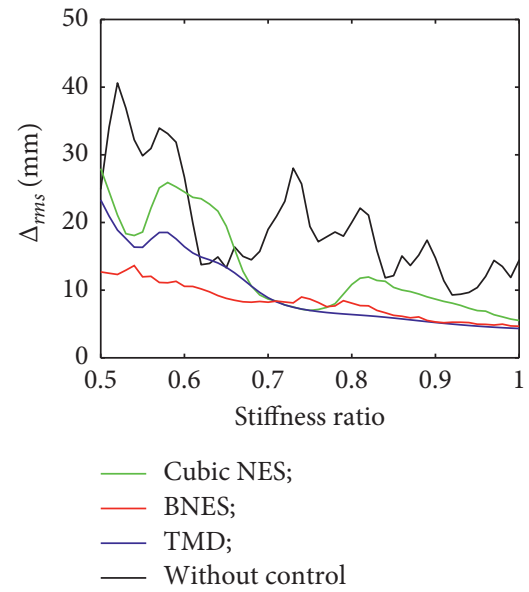

(f)

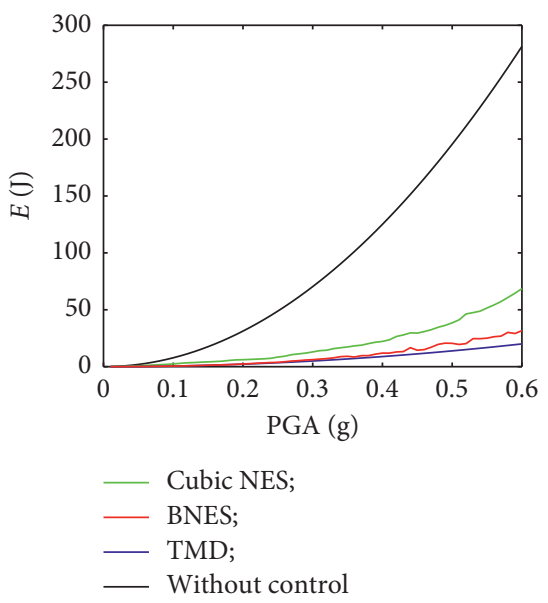

(i)

FIGURE 12: Response trends with parameter variations of the SDOF primary structure: (a) Loma Prieta, 0.3 g; (b) Kobe, 0.3 g; (c) Chi-Chi, 0.3 g; (d) Loma Prieta, 0.3 g; (e) Kobe, 0.3 g; (f) Chi-Chi, 0.3 g; (g) Loma Prieta; (h) Kobe; (i) Chi-Chi.

rapidly absorbed and dissipated in about 17 seconds, after which the response of the structure becomes much weaker. Due to the broad frequency composition of the seismic wave, there is still some response energy distributed other than the natural frequency of the primary structure but is very weak.

In contrast to the linear TMD system, where the energy is only dissipated near the identical tuning frequency, energy 


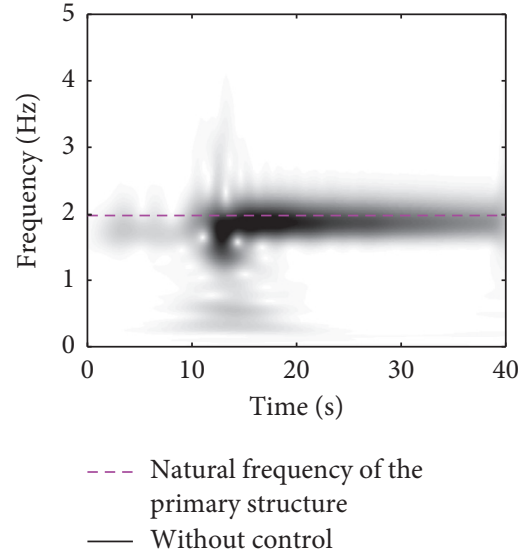

(a)

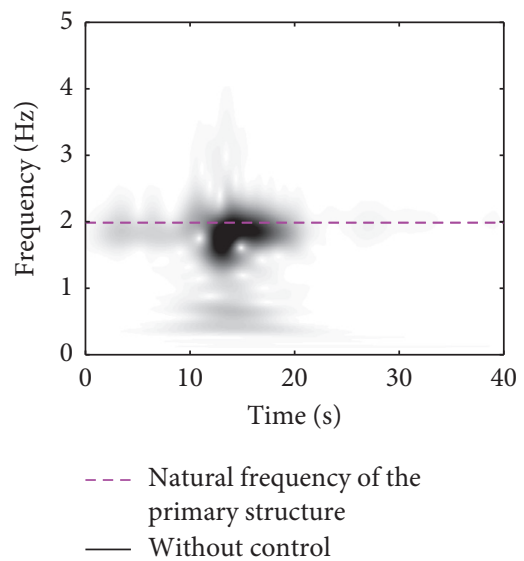

(d)

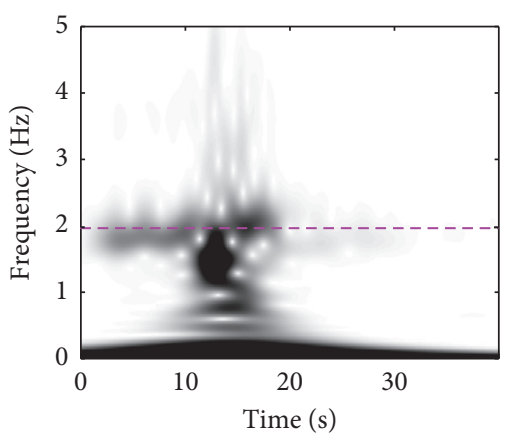

- - - Natural frequency of the primary structure

_ Without control

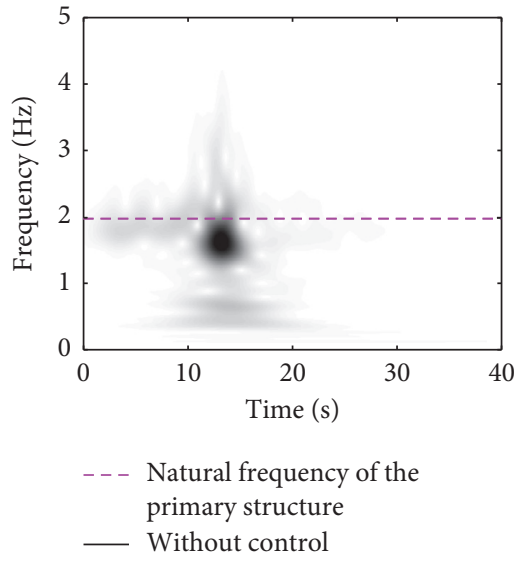

(b)

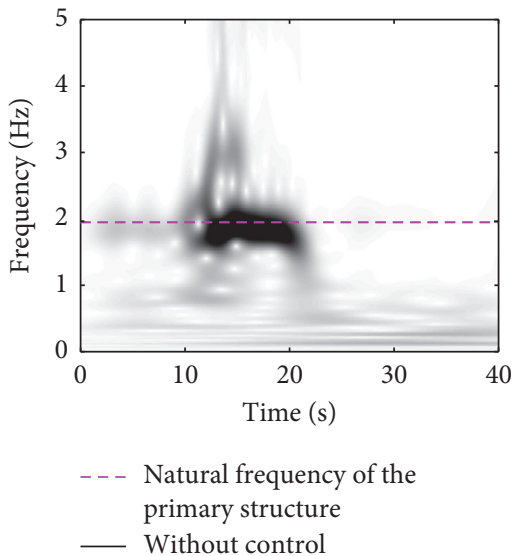

(e)

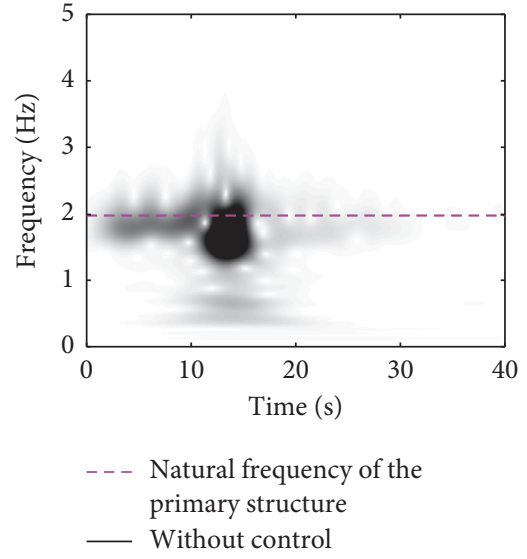

(c)

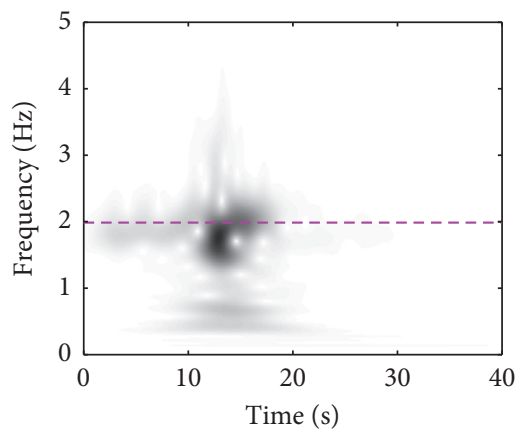

- - Natural frequency of the primary structure Without control

(f)

(g)

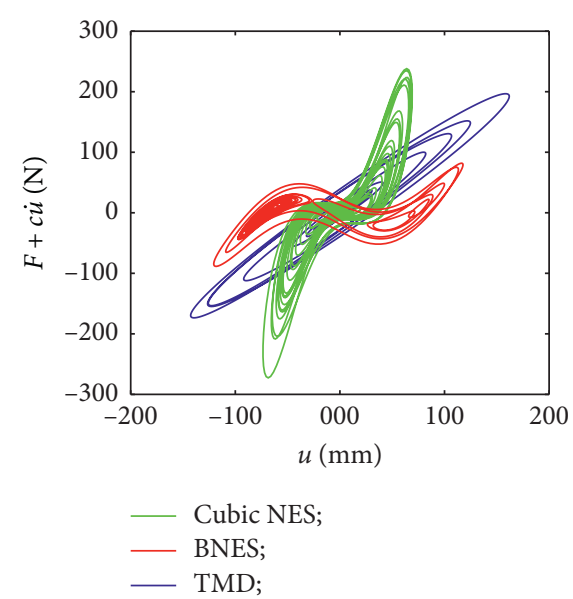

(h)

FIGURE 13: Numerical wavelet transforms of displacement response and BNES drift history under Loma Prieta wave, under the ideal condition: (a) primary structure without control; (b) primary structure under TMD control; (c) TMD; (d) primary structure under cubic NES control; (e) cubic NES; (f) primary structure under BNES control; (g) BNES; (h) hysteretic loops.

distributions in wider frequency domains can be observed in the NES systems from Figure 13(d)-13(g). This is especially true for a NES system where the optimized nonlinear system provides an effective mean of transferring vibration by transient internal resonance in broadband, which will never be triggered by a linear system. However, Figure 13(d) and 13(e) reveals that the internal resonance capture by the cubic NES is yet too weak to achieve highly transient internal resonance. From Figure 13(g) we can see that the cascade of transient internal resonance capture was drastically enhanced by present BNES, which underlines the reason for much higher and faster vibration absorption by the device. 


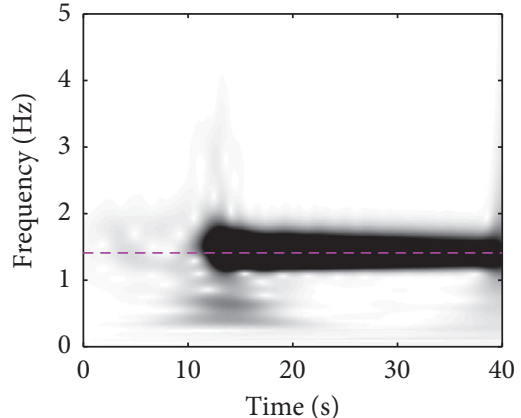

- - - Natural frequency of the primary structure

W Without control

(a)

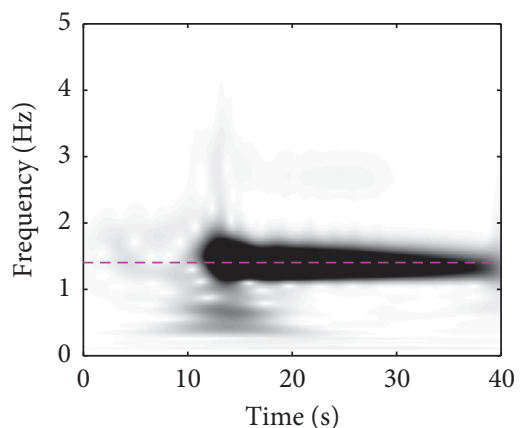

- - - Natural frequency of the primary structure Without control

(d)

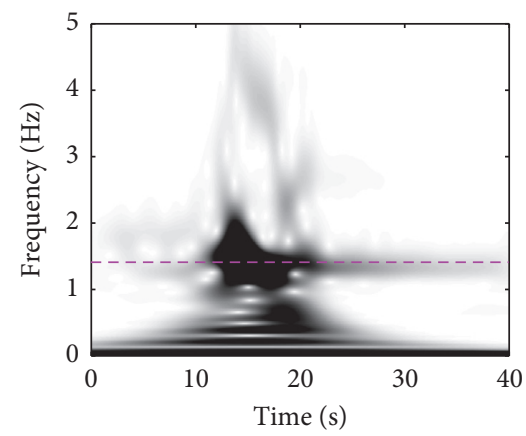

- - - Natural frequency of the primary structure

- Without control

(g)

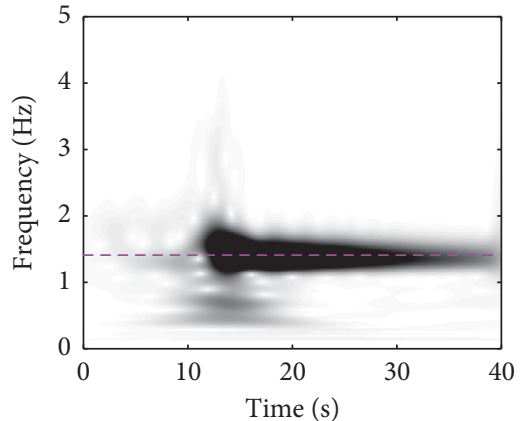

- - - Natural frequency of the primary structure

- Without control

(b)

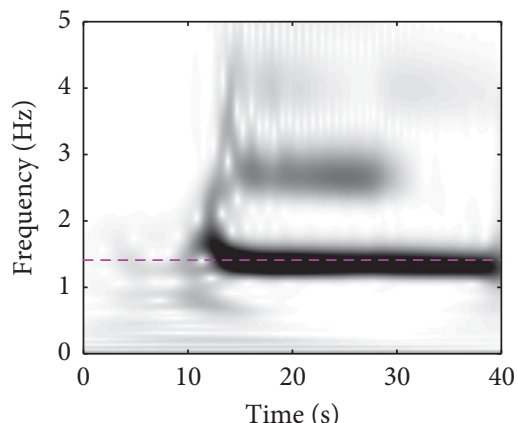

- - - Natural frequency of the primary structure

- Without control

(e)

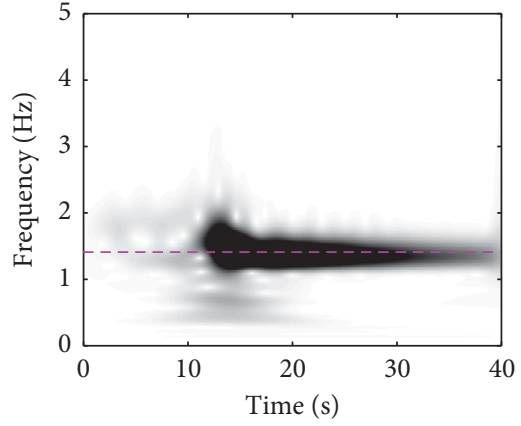

- - - Natural frequency of the primary structure

Without control

(c)

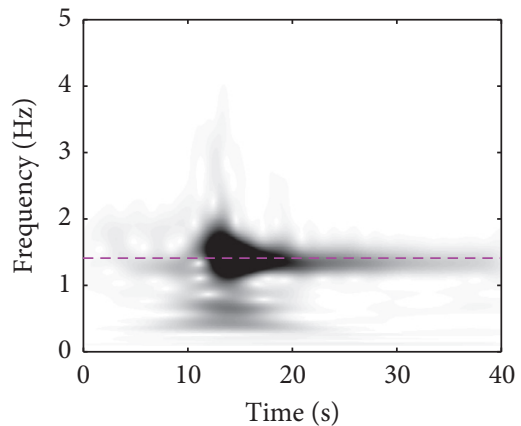

- - - Natural frequency of the primary structure W Without control

(f)

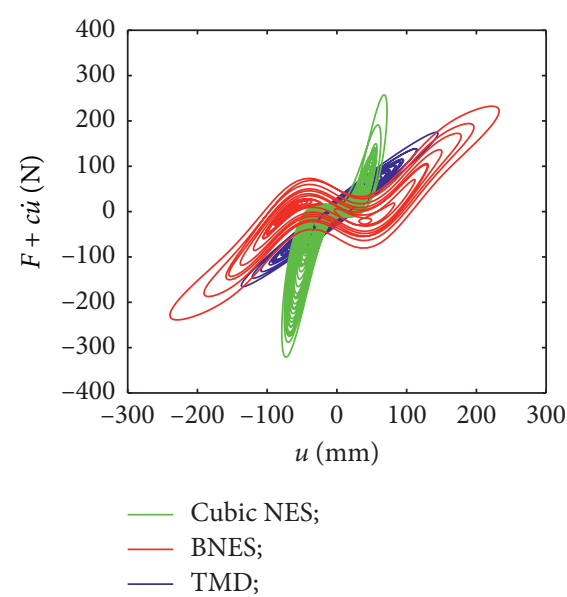

(h)

FIGURE 14: Numerical wavelet transforms of displacement response and BNES drift history under Loma Prieta wave, with 50\% stiffness loss of the primary structure: (a) primary structure without control; (b) primary structure under TMD control; (c) TMD; (d) primary structure under cubic NES control; (e) cubic NES; (f) primary structure under BNES control; (g) BNES; (h) hysteretic loops.

Particularly, compared with cubic NES or impact-type NES, the BNES system enables a very strong subfrequency internal resonance process in low-frequency domains.

Figure 13(h) shows the hysteretic loops of the attached oscillators, in which the jumping phenomena of the BNES mass during seismic excitation can be observed. We can see that, once the input seismic energy reaches a certain level, the moving BNES mass can be driven to escape the attraction of one stable equilibrium and jump into the other. If such escape happens, the moving mass drops into the negative stiffness interval and triggers cross-well vibration between the equilibriums. This corresponds to the cascade of internal 


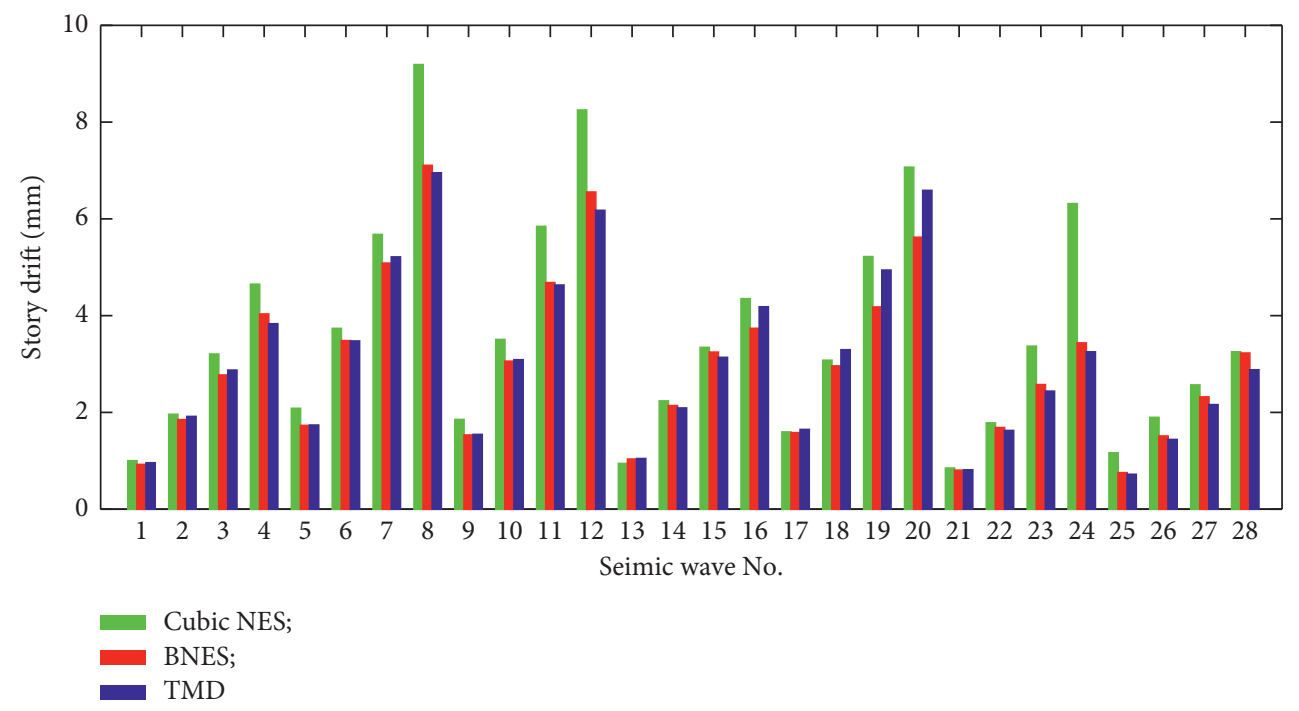

(a)

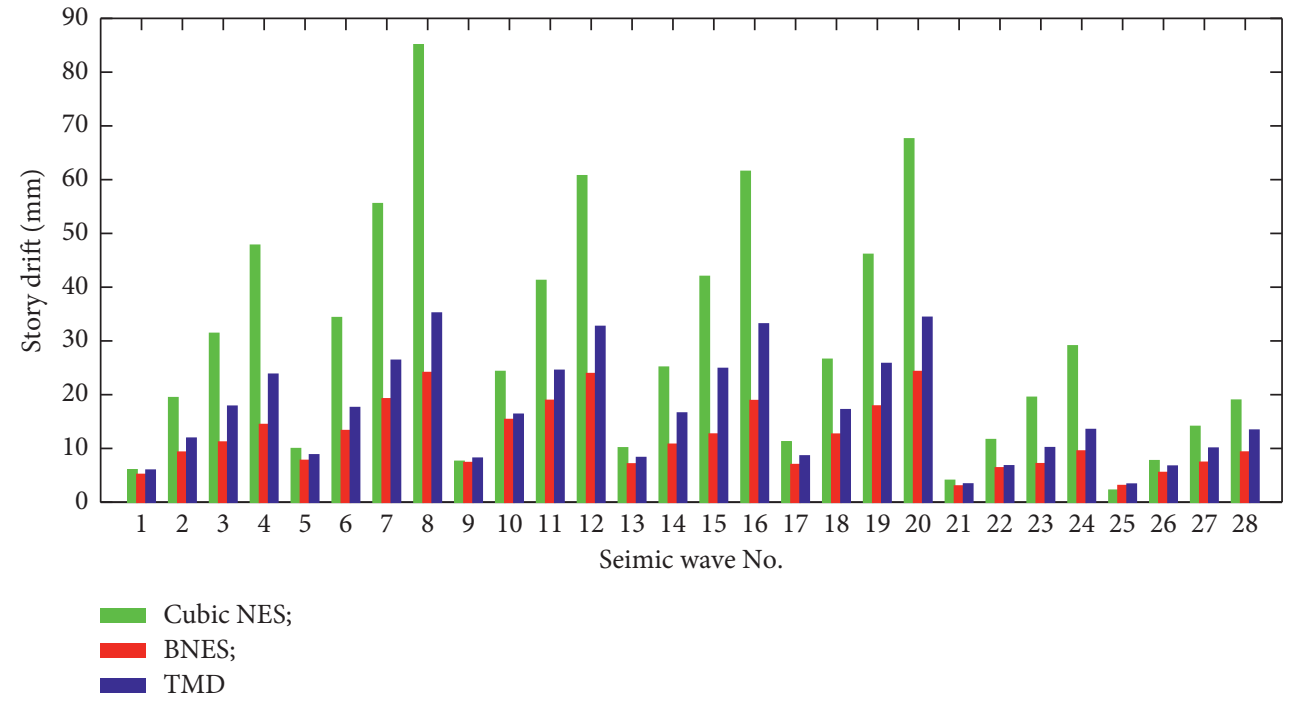

(b)

FIGURE 15: RMSs of story drift of the TDOF primary structure: (a) ideal design condition and (b) 50\% stiffness loss.

resonance observed in Figure 13(g). Similar phenomena can also be found in the BNES study under impulsive excitation in Ref [23].

Furthermore, Figure 14 is given to investigate the case under 50\% stiffness loss of the SDOF primary structure. Figure 14(a) verifies the natural frequency deviation after the stiffness degradation. As shown in Figure 14(b) and 14(c), due to detuning of the TMD system, the response of the primary DOF at the natural frequency lasts in much longer time. Furthermore, from Figure 14(d) and 14(e), it can be seen that the loss of stiffness also induces deterioration of cubic NES control.

However, in Figure 14(f) and 14(g), it can be seen that the BNES still maintains the cascade of internal resonance capture in strong level, in spite of the stiffness loss of the primary structure. This is reasonable because in contrary to those narrow band resonances of linear system, the wideband response characteristic of the cascade of internal resonance endues its insensitivity to frequency variation of the primary structure. This consequently enables the robustness of the control performance by the BNES. Figure 14(h) presents the hysteretic loops of different control devices during the seismic response. The long-distance damping strokes of the BNES mass under cross-well vibration can still be observed, which rapidly absorb the seismic response of primary SDOF.

4.2. Two-Story Structure. Performance characteristics are also studied for the TDOF primary structure. Compared with the results for the SDOF primary structure, similar behaviors of the control systems are derived. The RMSs of story drift under different control systems are presented in Figure 15, for the ideal condition and for 50\% stiffness loss of 
the primary structure, respectively. In Figure 15(a) it can be seen that the BNES and the in-tuned TMD system totally provide preferable performance for story drift reduction.

The cubic NES yet shows lower efficiency in the most cases. Particularly, it can also be seen in Figure 15(b) that, in detuned conditions, the TMD rapidly loses the control efficiency, while the present BNES can still maintain the suppression effect for the story drift response of the TDOF primary structure to the lowest level.

\section{Conclusions}

Linear or equivalently linear TMD has been used as effective passive vibration control devices for seismic application. However, the effectiveness of the TMD sensitively depends on the tuning conditions of the structural system. In reality, perfect tuning of the device to account for all the uncertainties is unrealistic. In this paper, a magnetic BNES is proposed. The present BNES utilizes permanent magnets with a moving mass connected using linear springs to dissipate the earthquake energy. Different from those impact types of NES which scatter the seismic energy in high frequency domains by instant impacts, the present BNES efficiently works with any impact avoided. The bistable property enhances the capacity of transient internal resonance capture of the BNES device in broadband. The essential working mechanism of the present BNES under seismic excitation can be attributed to the cascade of transient internal resonance. The strong robustness of the present BNES is due to the insensitivity of the broadband transient internal resonance to condition variation of the primary structure.

To examine the performance of the BNES, the performance of a one-story shear building and a two-story shear building were compared with the TMD and NES. The results show that the proposed BNES can outperform the TMD and the cubic NES. In the idealized tuned condition, the linear TMD and the BNES possesses efficient control of seismic response of the primary structure. In the detuned condition, the linear TMD becomes inefficient, but the BNES maintains good controlling performance with respect to stiffness degradation of the primary structure. The cubic NES totally behaves in lower efficiency in the comparison study. The present BNES rapidly improves the robustness behavior of NES with respect to PGA variations. Overall, this paper demonstrates that the proposed BNES is a robust vibration control device, which can be used effectively for seismic engineering applications. The essential study of chaotic motion of the present BNES under earthquake excitation will be studied in our further work.

\section{Data Availability}

Some or all data, models, or codes that support the findings of this study are available from the corresponding author upon request.

\section{Conflicts of Interest}

The authors declare that they have no conflicts of interest.

\section{Acknowledgments}

The financial supports from the National Key R\&D Program of China (2017YFC0703600), the Natural Science Foundation of China (12072130), and the Natural Science Foundation of Guangdong Province (2016A030313544) are gratefully acknowledged by the authors.

\section{References}

[1] A. F. Vakakis, O. V. Gendelman, L. A. Bergman, D. M. McFarland, G. Kerschen, and Y. S. Lee, Nonlinear Targeted Energy Transfer in Mechanical and Structural Systems I \& II, Springer, Berlin, Germany, 2008.

[2] O. Gendelman, L. I. Manevitch, A. F. Vakakis, and R. M'Closkey, "Energy pumping in nonlinear mechanical oscillators: Part I-dynamics of the underlying Hamiltonian systems," Journal of Applied Mechanics, vol. 68, no. 1, pp. 34-41, 2001.

[3] A. F. Vakakis and O. Gendelman, "Energy pumping in nonlinear mechanical oscillators: Part II-resonance capture," Journal of Applied Mechanics, vol. 68, no. 1, pp. 42-48, 2001.

[4] D. M. Mcfarland, L. A. Bergman, and A. F. Vakakis, "Experimental study of non-linear energy pumping occurring at a single fast frequency," International Journal of Non-linear Mechanics, vol. 40, no. 6, pp. 891-899, 2005.

[5] E. N. Gourdon, A. Alexander, C. A. Taylor, C. H. Lamarque, and S. Pernot, "Nonlinear energy pumping under transient forcing with strongly nonlinear coupling: theoretical and experimental results," Journal of Sound and Vibration, vol. 300, no. 3-5, pp. 522-551, 2007.

[6] N. E. Wierschem, J. Luo, M. Al-Shudeifat, S. Hubbard, R. Ott, and L. A. Fahnestock, "Experimental testing and numerical simulation of a six-story structure incorporating two-degreeof-freedom nonlinear energy sink," ASCE Journal of Structural Engineering, vol. 140, pp. 1-10, Article ID 04014027, 2014.

[7] J. Wang, N. E. Wierschem, B. F. Spencer, and X. Lu, “Track nonlinear energy sink for rapid response reduction in building structures," Journal of Engineering Mechanics, vol. 141, no. 1, Article ID 04014104, 2015.

[8] J. Wang, N. Wierschem, B. F. Spencer, and X. Lu, "Experimental study of track nonlinear energy sinks for dynamic response reduction," Engineering Structures, vol. 94, pp. 9-15, 2015.

[9] X. Lu, Z. Liu, and Z. Lu, "Optimization design and experimental verification of track nonlinear energy sink for vibration control under seismic excitation," Structural Control and Health Monitoring, vol. 24, no. 12, 2017.

[10] M. A. Al-Shudeifat, "Asymmetric magnet-based nonlinear energy sink," Journal of Computational and Nonlinear Dynamics, vol. 10, no. 1, Article ID 014502, 2015.

[11] D.-D. Tan, Z.-Q. Lu, D.-H. Gu, H. Ding, and L.-Q. Chen, “A ring vibration isolator enhanced by a nonlinear energy sink," Journal of Sound and Vibration, vol. 508, Article ID 116201, 2021.

[12] F. Nucera, F. L. Lacono, D. M. Mcfarland, L. A. Bergman, and A. F. Vakakis, "Application of broadband nonlinear targeted energy transfers for seismic mitigation of a shear frame: experimental results," Journal of Sound and Vibration, vol. 313, no. 1, pp. 57-76, 2008.

[13] F. Nucera, D. M. Mcfarland, L. A. Bergman, and A. F. Vakakis, "Application of broadband nonlinear targeted energy transfers for seismic mitigation of a shear frame: computational 
results," Journal of Sound and Vibration, vol. 329, no. 1, pp. 2973-2994, 2010.

[14] M. Ahmadi, K. Attari, and M. Shahrouzi, "Structural seismic response mitigation using optimized vibro-impact nonlinear energy sinks," Journal of Earthquake Engineering, vol. 19, no. 2, pp. 193-219, 2014.

[15] O. V. Gendelman and A. Alloni, "Dynamics of forced system with vibro-impact energy sink," Journal of Sound and Vibration, vol. 358, pp. 301-314, 2015.

[16] T. Li, S. Seguy, and A. Berlioz, "On the dynamics around targeted energy transfer for vibro-impact nonlinear energy sink," Nonlinear Dynamics, vol. 87, pp. 1-14, 2016.

[17] F. Schmidt and C.-H. Lamarque, "Energy pumping for mechanical systems involving non-smooth Saint-Venant terms," International Journal of Non-linear Mechanics, vol. 45, no. 9, pp. 866-875, 2010.

[18] C. H. Lamarque and A. T. Savadkoohi, "Targeted energy transfer between a system with a set of saint-venant elements and a nonlinear energy sink," Continuum Mechanics and Thermodynamics, vol. 27, no. 4, pp. 819-833, 2015.

[19] J. Luo, N. E. Wierschem, S. A. Hubbard et al., "-scale experimental evaluation and numerical simulation of a system of nonlinear energy sinks for seismic mitigation," Engineering Structures, vol. 77, pp. 34-48, 2014.

[20] J. Wang, N. E. Wierschem, B. F. Spencer, and X. Lu, "Numerical and experimental study of the performance of a single-sided vibro-impact track nonlinear energy sink," Earthquake Engineering \& Structural Dynamics, vol. 45, no. 4, pp. 635-652, 2016.

[21] M. A. Al-Shudeifat, "Highly efficient nonlinear energy sink," Nonlinear Dynamics, vol. 76, no. 4, pp. 1905-1920, 2014.

[22] L. I. Manevitch, G. Sigalov, F. Romeo, L. A. Bergman, and A. Vakakis, "Dynamics of a linear oscillator coupled to a bistable light attachment: analytical study," ASME Journal of Applied Mechanics, vol. 81, no. 4, Article ID 041011, 2014.

[23] F. Romeo, G. Sigalov, L. A. Bergman, and A. F. Vakakis, "Dynamics of a linear oscillator coupled to a bistable light attachment: numerical study," ASME Journal of Computational and Nonlinear Dynamics, vol. 10, no. 1, Article ID 011007, 2015.

[24] X. Fang, J. Wen, and J. Yin, "Highly efficient continuous bistable nonlinear energy sink composed of a cantilever beam with partial constrained layer damping," Nonlinear Dynamics, vol. 87, no. 4, pp. 2677-2695, 2017.

[25] D. Qiu, T. Li, S. Seguy, and M. Paredes, "Efficient targeted energy transfer of bistable nonlinear energy sink: application to optimal design," Nonlinear Dynamics, vol. 92, no. 2, pp. 443-461, 2018.

[26] H. Allag and J. P. Yonnet, "3-D analytical calculation of the torque and force exerted between two cuboidal magnets," IEEE Transactions on Magnetics, vol. 45, no. 10, pp. 39693972, 2009. 